\title{
The Effects of a Fat Tax on French Households' Purchases: A Nutritional Approach
}

\author{
Oliver Allais $^{a, *}$, Patrice Bertail ${ }^{b}$, and Véronique Nichèle ${ }^{a}$ \\ ${ }^{a}$ INRA-ALISS, UR1303, F-94205 Ivry-sur-Seine, France. \\ ${ }^{b}$ MODAL'X, Université Paris X and CREST-LS. \\ *INRA-ALISS, 65, Bd de Brandebourg, F-94205 Ivry-sur-Seine, \\ Tel: 33-1-49-59-69-31 - Fax: 33-1-49-59-69-90, \\ Email: allais@ivry.inra.fr
}

\begin{abstract}
This article assesses the effects of a "fat tax" on the nutrients purchased by French households across different income groups. This is done by making a preliminary estimation of price elasticities using a complete demand system on household scanner data, and by calculating nutrient elasticities using estimated price elasticities. We find that a fat tax has small and ambiguous effects on nutrients purchased by French households, and a slight effect on body weight in the short run, with a greater effect in the long run. Such a tax generates substantial tax revenue, but is highly regressive.

Key words: AI demand system, cohort, fat tax policy, household survey data, missing data, nutrient elasticities

JEL classification: D12, C33

Acknowledgements: The authors would like to thank the editor, Wally Thurman; two anonymous referees; Boizot, C., Caillavet, F., Darmon, N., Etilé, F., Lecocq, S, Nayga, R., Rickertsen, K., Simioni, M., and Soler, LG.; and participants of the INRA-IDEI Workshop on Economics of Obesity. This research has benefited from a grant from the INRA-INSERM program "A.T.C.
\end{abstract} Nutrition." 
The World Health Organization (WHO) has recognized obesity and overweight as major worldwide public health concerns (WHO, 2000). In France, Paraponaris, Saliba, and Ventelou (2005) assessed that the percentage of overweight or obese individuals had increased since 1980 from 32.9 to 37.5 for overweight and from $6.3 \%$ to $9.9 \%$ for obese in 2003. In 1992, Detournay et al. (2000) and Levy et al. (1995) estimated the medical cost of obesity in France to be in the range $0.6-1.1$ billion euros, which represented $0.7-1.5 \%$ of the country's total health expenditures. The growing rate of obesity and the resulting economic externalities have led French health authorities to explore market interventions, such as taxes and subsidies, to modify food consumption and consequently body weight. In particular, French state policy makers (IGF-IGAS, 2008) are questioning the efficacy of a special tax on food items high in calories, fat, or sugar-a "fat tax"-on household nutrient purchases. The objectives of this public policy measure are to decrease the sale of unhealthful food products, or at least to function as a disincentive to eating such products, and to generate revenue earmarked to support such health measures as subsidizing healthful foods, increasing physical activity, providing nutrition education, etc.

The objective of this study was to quantify the relevance and efficacy of a fat tax in France. We did this by answering three sets of questions: (1) What are the impacts of a fat tax on household purchases and nutrients purchased, and what are the short- and long-run effects of this tax on body weight? Although it seems intuitive that increasing the effective price of unhealthful foods should discourage their purchase, the whole impact of this increase on nutrients purchased, and especially on calories and total fat purchased, is not clear, given that food purchases are highly interdependent. ${ }^{1}$ (2) How much revenue would such a tax raise? (3) How much would such a tax affect household economic welfare in the short term, and how regressive a political instrument is it? To answer these questions, we needed to assess how food prices affect food demand and nutrient purchases. In other words, price and nutrient elasticities needed to be estimated. We did this by estimating a complete Almost Ideal (AI) demand system using French household data collected by TNS Worldpanel between 1996 and 2001. ${ }^{2}$ The study period was chosen to quantify the 
effects of the fat tax before the implementation of the first national nutrition and health program in France. ${ }^{3}$ Thus, the effects of informational programs are not included in our analysis.

Most applied research heretofore has been based on incomplete food demand systems using either some strong separability assumptions, as in Bertail and Caillavet (2008), or methodology developed by LaFrance and Hanemann (1989), and thereby only partially assesses the price effects on purchases, in particular the trade-offs between various food items and/or nutrients. ${ }^{4}$ For this article, a complete food demand system, which allows us to consider a very large set of interdependent demand relationships, was estimated to assess the global impact of a fat tax on households' nutrient purchases. To estimate a complete food demand model, we needed to have complete information (prices, expenditures, budget shares, etc.) over a large set of food items for all sampled households. However, expenditures, quantities, and supply prices for some food items for any given household are not recorded in TNS Worldpanel data. To solve the problem of data incompleteness, we proposed a cohort model obtained by aggregating the AI demand system over cohorts. ${ }^{5}$ The crucial step in this approach was to estimate the unobserved variables using a pre-model over cohorts. One of the technical contributions of this article is to show how the aggregation process leads to induced bias and heteroscedasticity.

In this study, we estimated nutrient elasticities for 32 nutrients in response to changes in 22 food category prices over cohorts for the period 1996-2001. In particular, we segmented households into six regions of residence and four income groups. We then used Huang's (1996) methodology, which consists of applying a nutrient conversion matrix to the price elasticities, to derive nutrient elasticities. Finally, the latter were used to see whether a fat tax reduces households' total energy purchases and to quantify the associated trade-offs between nutrients. In similar works, Marshall (2000), and Mytton et al. (2007) for Great Britain and Chouinard et al. (2007) for the U.S. assessed the impact of a fat tax on household nutrient purchases. For France, Bonnet, Dubois, and Orozco (2008) and Etilé (2008) estimated the price elasticity of body mass index (BMI) to quantify the 
impact of a fat tax. However, all these empirical studies restrict their analysis to a small set of nutrients, and trade-offs between nutrients are therefore only partially assessed.

The household food-acquisition data contained in the TNS Worldpanel database has advantages over individual food surveys more commonly used to study the relationships between food and health in France. Households respond over a longer period of time (an average of four years in the TNS Worldpanel survey), which enables the observation of long-term behaviors and avoids the well-known biases of individual food surveys. In individual surveys, respondents may over- or underreport their consumption of certain foods of high or low nutritional value, respectively, either because they prefer to conceal the truth or because they do in fact deliberately increase or reduce their consumption for the short period of the survey. However, these data do not take into account the effects of food consumed away from home and do not reach the level of individual choice. Chesher (1997) and Allais and Tressou (2008) developed nonparametric methods to decompose a series of household quantities into individual quantities. But in light of the incompleteness of our database and the errors of approximation that follow from decomposition methods, as underscored in Allais and Tressou (2008), we chose not to use these methods in the present study.

We found that, to have the greatest impact on households' total energy, cheese, butter, and cream, sugar-fat products, and prepared meals should be taxed, and that taxing these goods does reduce total calories purchased, via, in particular, the decrease in the amount of saturated fats purchased. But the effects are small and ambiguous-ambiguous because increasing the price of a food to reduce calories purchased generally also reduces purchases of other nutrients deemed good for health. Even more important, we found nutrient price elasticities to be remarkably inelastic, as in Huang and Lin (2000) and Beatty and LaFrance (2005). These results call into question the effectiveness of tax policies intended to alter nutritional intakes, as highlighted by Mytton et al. (2007) and Chouinard et al. (2007), and are consistent with the conclusions of Kuchler, Tegene, and Harris (2005) and Kuchler et al. (2005) for household food purchases. Regarding the im- 
pact of a fat tax on weight, we estimated that a $10 \%$ tax on food categories high in calories leads to quite small changes in the short run, with more substantial changes in the long run. However, in some cases, it could take more than seven years to achieve the longterm effects. Given that the taxed products are inelastic, fat-tax policies raise substantial revenues but, like Chouinard et al. (2007), we found that this political instrument can be extremely regressive.

This article is organized as follows: We begin by presenting the data and the cohort construction, and then describe the estimation over cohorts of the unobserved data. Third, we lay out the aggregation procedure for the AI demand system and highlight the resulting estimation problems. Fourth, we present the estimation results and the demand and nutrient elasticities. Fifth, we assess the fat-tax policy based on changes in the purchases of 32 nutrients; short- and long-run variations in weight; level of revenue raised by the tax; and household-welfare costs. Finally, we conclude by wondering how the food industry would respond to a fat-tax policy, and whether it might be more effective to use the credible threat of a fat tax to urge voluntary approaches by the food industry to reduce calories in food products, via decreasing saturated-fat content.

\section{Data and Cohort Construction}

This section begins with a presentation of the data used and an explanation of why the construction of cohorts was needed to estimate a complete food demand system in France. Then we detail the construction of the cohort.

\section{The Data}

TNS Worldpanel is the principal source of information on food purchases in France. Each annual survey contains weekly food-acquisition data for approximately 5,000 households, with an annual rotation of one-third of the participants. The households are selected by stratification according to several socioeconomic variables, and remain in the survey for a mean period of four years. All participating households register grocery purchases through the use of bar codes. To register grocery purchases without a bar code, each 
household is assigned to one of two groups to alleviate its workload. Each group (half of the survey) is requested to register its purchases for a restricted set of products: meat, fish, and wine for the first group and fresh fruits and vegetables for the second group. Although the two lists together include nearly all possible food products at a very disaggregated level, the structure of the dataset means that purchasing information is never complete for a given household. In other words, for any given household, expenditures, quantities, and supply prices are missing for some food categories. Complete demand systems cannot consequently be estimated, and it is then impossible to estimate the global impact of price reforms on household behavior, particularly for the product substitutions that these reforms seek to encourage. To solve the problem of data availability resulting from data structuring, we used cohorts, as proposed by Deaton (1985). How cohorts were constructed is presented below. The complete demand system, based on cohort data, was then estimated using four-week-period data over 1996-2001.

To facilitate the estimation procedure and to reduce the number of parameters to be estimated, we grouped food items into 22 categories. We considered carefully how to categorize different foods, taking into account similarities in the nutritional content of the products, consumer preferences, and consumer willingness to substitute one product for another. The following categories of goods were defined: red meat (beef and veal); other meats (poultry, pork, lamb, etc.); cooked meats (ham, pâté, sausages, bacon, etc.); fish and seafood; eggs; grain products (bread, pasta, rice, wheat flour, and cereals); potatoes; fresh fruits; processed fruits; dried fruits; fresh vegetables; processed vegetables; milk products (milk, cream, yoghurt, dairy desserts, etc.); cheese, butter, and cream; prepared meals (pizza, sauerkraut, cassoulet, etc.); oils; salt-fat products (finger food, chips, crackers, appetizers); sugar-fat products (candy, chocolate, cookies, pastry, ice cream, jam, etc.); mineral and spring waters; fruit juices; other soft drinks (sodas, lemonade, syrups, etc.); and alcoholic beverages (including wine). The online appendix provides a detailed discussion of why we chose this classification. 
All the quantities and prices of these categories of goods were expressed in the same units (kilogram and French franc per kilogram) to ensure that the demand model used to estimate elasticity is "closed under unit scaling" (CUUS), meaning that the estimated economic effects are invariant to a simultaneous change in unit, as stressed by Alston, Chalfant, and Piggott (2001).

We then determined the quantities of the 32 nutrients in the 22 food categories, based on consultations with nutritionists and on the composition tables of food products developed by Favier et al. (1995). The nutrients of interest are energy (measured in food calories); fat, subdivided into saturated (red meat, egg, whole milk, etc.), monounsaturated (olive oil, canola oil, peanut oil, etc.), and polyunsaturated (oils from corn, soybean, safflower, cottonseed, fish, etc.); cholesterol and alcohol; proteins, subdivided into vegetable and animal protein; carbohydrates; dietary fibers; micronutrients such as vitamin A (retinol and beta-carotene), B vitamins $(1,2,3,5,6,9,12)$, vitamin $C$, vitamin $D$, and vitamin $E$; and minerals (calcium, iron, magnesium, sodium, phosphorus, potassium).

\section{Cohort Construction}

The population is split into homogeneous cohorts based on the following two variables:

(1) A geographical variable that indicates the region of residence of the household. Adjacent regions where traditions and food-purchasing patterns show significant similarities were grouped together. In particular, we aggregated regions by comparing the main food categories that are over- or underpurchased relative to the associated national average purchase. For example, we aggregated the North (North-Pas de Calais, Picardy) and Northeast (Lorraine, Alsace, Champagne-Ardenne) into one because both regions show overpurchases of meat, cooked meat, potatoes, and cheese/butter/cream, and underpurchases of fresh fruits, fresh vegetables, and fish. This approach led to six regional modalities: Paris and its suburbs; the North and Northeast; the Southeast (ProvenceAlps-Côte d'Azur, South Rhône Alps departments, i.e., Ardèche, Drôme); the Southwest (Poitou-Charente, Aquitaine, Midi-Pyrenees, Languedoc-Roussillon) and Limousine and 
Auvergne; the West (Brittany, Western Loire, Normandy); and the Center-East (Centre, Burgundy, Free County of Burgundy, East Rhône-Alps departments, i.e., Savoy, Upper Savoy, Isère). More details on how region selection was implemented, as well as more results, are given in the online appendix.

(2) A socioeconomic classification of the households constructed by TNS Worldpanel. This variable is based on a household's monthly income with respect to its number of members and to consumption units defined by the Organisation for Economic Co-operation and Development (OECD). This classification scheme comprises four modalities: well-off, those households with the highest levels of income; average upper, households whose income is above the national average; average lower, households whose income is below the national average; and modest, households with low income levels. The intervals of household monthly income chosen by TNS Worldpanel data to characterize the four income classes are provided in the online appendix.

This set of variables enabled us to detect the likely differences in dietary patterns across income and regions of residence. We established 24 cells, which represent typical households for a given region and income level. Table 1 provides descriptive statistics of the number of households in cells.

\section{Estimation of the Unobserved Data}

We addressed the problem of unobserved data by using cohorts. Unobserved quantities purchased and expenditures in the 22 food categories defined above were estimated for 13 four-week periods over six years. The estimates were based on the mean purchase and price values over all households in a given cohort, as detailed below.

\section{Estimation of Unobserved Quantities and Expenditures}

In the following discussion, $\mathscr{S}_{k}, k=1,2,3$ stands for, respectively, the subpanel corresponding to Group 1 (meat, fish, and wine), the sub-panel corresponding to Group 2 (fresh fruits and vegetables), and, finally, the subpanel of products that are registered by all households. Note that a household appears either in both subpanels $S_{1}$ and $S_{3}$ or 
sub-panels $S_{2}$ and $S_{3}$. Moreover, we denote $\mathscr{P}(i)=\mathscr{S}_{l}$ if $i \in \mathscr{S}_{l}$. So writing $h \in \mathscr{P}(i)$ (respectively, $h \in \mathscr{P}(i)^{c}$ ) means that the household $h$ has (respectively, has not) registered the product $i$.

In the TNS Worldpanel dataset, we never observe the full consumption of any given household basket. Thus, items were aggregated at the cohort level using the following procedures: For a given cohort $c \in\{1, \ldots, C=24\}$, at time $t \in\{1, \ldots, T=78\}$, we observe $N_{c, t}$ households in the corresponding cohort denoted $H_{c, t}$. Let $Y_{i h t}$ be some variable of interest in a food category $i$ of a household $h$ at period $t$ that is observed only in the subpanel $\mathscr{S}_{l}, l=1,2,3$. The unobserved value for a household $h$ at period $t$ who belongs to the cell $H_{c, t}$ but who does not register the product $i$ is predicted by the mean $\bar{Y}_{i c t}$, over the households in a cell $c$ at period $t$ to whom product $i$ is registered.

\section{Estimation of Unobserved Prices}

As with food quantities purchased, supply prices are not completely captured in the TNS Worldpanel database. Generally, food prices are approximated by unit values obtained by dividing expenditures by quantities purchased for a given good. In the present study, however, unit values cannot be calculated for each household since we do not observe all the expenditures and quantities purchased for any given household. Second, the unit value is not the supply price of a good, as it reflects both its average market price and consumer choices of food quality: two different households subject to the same pricing scheme may well exhibit different unit values because food items purchased by households have different qualities.

We addressed the first problem by approximating the unobserved quantities and expenditures for any given household using the cohort method described above. Yet unlike unobserved quantities and expenditures, unit values were constructed across regions to capture variations in market prices induced by transportation costs. This means that unit values within regions are constant. This aggregation process also attenuated the second problem. The unit values that it provided are used below as prices for households. 
The second problem was further addressed using a procedure similar to that of Park and Capps (1997). Prices were quality-adjusted by regressing the log of unit values on total household food expenditures and household characteristics that may affect the choice of food quality, such as income level, household composition and size, and the education level of principal earner. We found significant food-quality effects for all food groups, with the exception of red meat, fish, potatoes, processed fruits and vegetables, fruit juices, milk products, and salt-fat products, at the 5\% level. However, these effects are much smaller than those obtained by Huang and Lin (2000) since our study aggregated data over a longer period of time (four weeks vs. seven days) and for a larger group of consumers (aggregated across cohorts vs. no aggregation). The estimated food-quality effects across income can be found in the online appendix.

\section{Aggregating the AI Demand System: A Cohort Model}

The total household food expenditure cannot be directly calculated for a given household in the TNS Worldpanel database. As a consequence, this variable must be extrapolated for each cell. In the following discussion, we describe the AI model and propose a simple model for estimating the total household food expenditure of each household as well as the shares that will be compatible with the aggregation of the AI demand system. The consequences of the aggregation for the estimation, in terms of bias and heteroscedasticity, are carefully examined in the last subsection.

\section{The AI Model}

We focus here on a standard AI demand system developed by Deaton and Muellbauer (1980). Quadratic AI demand systems (Banks, Blundell, and Lewbel 1997) are more flexible, but the nonlinear quadratic term in these models makes them difficult to aggregate and estimate when considering cohorts. However, Banks, Blundell, and Lewbel show that the AI demand system is unlikely to be rejected for most food items. Other models, particularly in the framework of an incomplete demand system, have been proposed by LaFrance (1990), LaFrance et al. (2002), and Beatty and LaFrance (2005) based on the 
work of LaFrance and Hanemann (1989). The purpose of these models is essentially to propose incomplete demand models consistent with standard microeconomic theory. To avoid some complications induced by the nonlinearities in their models (see, for instance, the box-cox transformation model proposed in LaFrance et al. 2002), we did not apply any nonlinear transformation to our data prior to analyzing it. Another reason for not using this kind of model is that our database contains gaps in the unit values for all the households in our database. We now recall a few facts about the AI demand system.

In the framework of the household production model, the consumption behavior at the household level during period $t$ can be described with an AI demand system by replacing unit values for prices. As such, in this framework, the budget share $w_{i h t}$, for product $i$, household $h$, and time $t$ is given by

(1) $w_{i h t}=\mu_{i h}+\sum_{j=1}^{N} \gamma_{i j} \ln v_{j h t}+\beta_{i}\left[\ln x_{h t}-\ln a\left(v_{h t}\right)\right]+u_{i h t}$,

for $i=1, . ., N$ food categories and $h=1, . ., H$ households, where $a\left(v_{h t}\right)$ stands for the price index given by $\ln a\left(v_{h t}\right)=\mu_{0}+\sum_{i=1}^{N} \mu_{i h} \ln v_{i h t}+\frac{1}{2} \sum_{i, j=1}^{N} \gamma_{i j} \ln v_{i h t} \ln v_{j h t}$. The variable $v_{i h t}$ stands for the unit value of a category of goods $i$ for household $h$ at period $t$. The variable $x_{h t}$ stands for the total expenditure of household $h$ at period $t$; and $\alpha_{i}, \gamma_{i}$, and $\beta_{i}$ are the parameters to be estimated. To take into account the heterogeneity of behavior, the parameter $\mu_{i h}$ is modeled as a linear form $\mu_{i h}=\alpha_{i 0}+Z_{h} \alpha_{i}$, where $Z_{h}=\left(Z_{k h}, k=1, \ldots K\right)$ is a vector $(1, K)$ of household characteristics. We denote as $\mathscr{I}_{i h t}=\left\{\left(v_{j h t}\right)_{j=1, \ldots, N}, \ln \left(x_{h t}\right)\right.$, $\left.Z_{h}\right\}$ the set of all explanatory variables for the share $w_{i h t}$. It may be proved that this system is derived from some cost minimization if it satisfies the restrictions imposed by the properties of demands, i.e., additivity, homogeneity of degree zero in prices and total household food expenditures together, and the symmetry of Slutsky's matrix. This implies the well-known additivity constraints $\sum_{i=1}^{N} \alpha_{i 0}=1, \sum_{i=1}^{N} \alpha_{i}=0, \sum_{i=1}^{N} \gamma_{i j}=0$, for all $j$ and $\sum_{i=1}^{N} \beta_{i}=0$ and the homogeneity and symmetry constraints $\sum_{j=1}^{N} \gamma_{i j}=0$, and $\gamma_{i j}=\gamma_{j i}$ for all $i$ and $j$. All the shares add up to one, giving us $\sum_{i=1}^{N} w_{i h t}=1+\sum_{i=1}^{N} u_{i h t}=1$. It follows that the $u_{i h t}$ perturbations are not independent. However, it is assumed that if we 
drop one share then the $u_{i h t}$ perturbations are independent conditionally to the whole information $\mathscr{I}_{i h t}$. Of course, this is a strong assumption that can be tested in future works. Even if these residuals are independent, they may not be identically distributed because of product or temporal effects.

\section{The Underlying Cell Models}

The AI demand system is based on budget share, which we cannot calculate at the household level in the present study because our database does not capture total household food expenditures. Nevertheless, we have sufficient information in our dataset to predict budget shares by aggregating over cells.

We assume that the expenditure of a household $h$ to purchase a product $i$ at time $t$ essentially depends on the characteristics of the cell to which the household belongs

$$
x_{i h t}=x_{i c t}+\varepsilon_{i h t}^{(1)}, \text { for } i=1, \ldots, N, h \in H_{c t}, c=1, \ldots, C, t=1, \ldots, T
$$

Here, the $x_{i c t}$ should be seen as the parameters of the model, i.e., the quantities to be predicted. To simplify, we assume that the expenditures of households are not correlated to each product. We also assume that the expenditures of any household in a given cell are not correlated over time. This is partially true insofar as the households that belong to $H_{c t}$ are generally not the same and are independent from the ones in $H_{c t^{\prime}}$, for $t^{\prime}$ and $t$ fardistant. We take into account that the partial correlation in a short period would make the estimation procedure more difficult. For a given household, $\varepsilon_{h t}^{(1)}=\left[\varepsilon_{i h t}^{(1)}\right]_{1 \leq i \leq N}$ has a variance $V\left(\varepsilon_{h t}^{(1)}\right)=\Omega_{t}$, where $\Omega_{t}=\left[\omega_{i j t}\right]_{1 \leq i, j \leq N}$ is an $N \times N$ full-rank matrix. For a given product $i$ and a time $t$, an estimator of $x_{i c t}$ is given by $\bar{x}_{i c t}=\frac{1}{N_{i c t}} \sum_{h \in H_{c t} \cap \mathscr{P}(i)} x_{i h t}$, where $N_{i c t}$ is the number of households in a cell $c$ at time $t$ for which product $i$ is registered. So, the best predictor of $x_{i h t}$ of a household that belongs to $H_{c t}$ and for which we do not observe the expenditure, $h \in \mathscr{P}(i)^{c}$ (equivalently $h \notin \mathscr{P}(i)$ ), is $\widehat{x}_{i h t}=\bar{x}_{i c t}$. It follows that total expenditure for a given household is predicted in an unbiased manner by

$$
\widehat{x}_{h t}=\sum_{i=1}^{N} x_{i h t} I_{h \in H_{c t} \cap \mathscr{P}(i)}+\sum_{j=1}^{N} \bar{x}_{j c t} I_{h \in H_{c t} \cap \mathscr{P}(j)^{c}}
$$


where $I_{A}$ stands for the indicator function of event $A$. Similarly, we define the total predicted expenditure over a cell as $\widehat{x}_{c t}=\sum_{i=1}^{N} N_{c t} \bar{x}_{i c t}$, where $N_{c t}$ is the number of households in the cell $c$ at period $t$.

Finally, the predicted household shares are given by $\widehat{w}_{i h t}=\frac{x_{i h t}}{\widehat{x}_{h t}}$ if $h \in \mathscr{P}(i) \cap H_{c t}$, and $\widehat{w}_{i h t}=\frac{\bar{x}_{i c t}}{\widehat{x}_{h t}}$ if $h \in \mathscr{P}(i)^{c} \cap H_{c t}$; the predicted shares over cells are given by $\widehat{w}_{i c t}=\frac{N_{c t} \bar{x}_{i c t}}{\widehat{x}_{c t}}$, which clearly satisfies the share equation $\sum_{i=1}^{N} \widehat{w}_{i c t}=1$.

\section{Aggregation of the AI Demand System Over Cells}

For aggregating the model, it is better to write the shares over cells $\widehat{w}_{i c t}$ as the weighted sums of household estimated shares. A simple calculation shows that $\widehat{w}_{i c t}=\sum_{h \in H_{c t}} \widehat{\theta}_{h c t} \widehat{w}_{i h t}$, where $\widehat{\theta}_{h c t}=\frac{\widehat{x}_{h t}}{\widehat{x}_{c t}}$ and satisfies $\sum_{h \in H_{c t}} \widehat{\theta}_{h c t}=1$. Gardes et al. (2005) propose the same aggregation process, but the main difference in their approach is that, in our study, the total household food expenditure is not known and $\widehat{\theta}_{h c t}$ estimates the true share $\theta_{\text {hct }}$. By aggregating model (1) over cells, i.e., by reweighing the shares with the estimated values $\widehat{\theta}_{h c t}$, for $h \in H_{c t}$, we get

$$
\widetilde{w}_{i c t}=\sum_{h=1}^{N_{c t}} \widehat{\theta}_{h c t} w_{i h t}=\alpha_{i 0}+\bar{Z}_{c, t} \alpha_{i}+\sum_{j=1}^{N} \gamma_{i j} \ln \bar{v}_{i r t}+\beta_{i}\left(\overline{\ln x}_{c t}-\overline{\ln \left(a\left(v_{r t}\right)\right)}\right)+\bar{u}_{i c t},
$$

where $\bar{Z}_{c t}=\sum_{h=1}^{N_{c t}} \widehat{\theta}_{h c t} Z_{h}$ is the weighted mean characteristic of a cell. By recalling the constancy of unit values within regions, the $\log$ unit value of product $j$ over a cell $c$ in region $r$, we have $\ln \bar{v}_{j c t}=\sum_{h=1}^{N_{c t}} \widehat{\theta}_{h c t} \ln \bar{v}_{i r t}=\ln \bar{v}_{i r t}$. The weighted mean total log expenditure of a cell is equal to $\overline{\ln }_{c t}=\sum_{h=1}^{N_{c t}} \widehat{\theta}_{h c t} \ln x_{h t}$, and, similarly, the weighted mean price index over a cell $c$ in region $r$ is equal to

$$
\overline{\ln \left(a\left(v_{r t}\right)\right)}=\mu_{0}+\sum_{i=1}^{N}\left(\alpha_{i 0}+\bar{Z}_{c t} \alpha_{i}\right) \ln \bar{v}_{i r t}+\frac{1}{2} \sum_{i, j=1}^{N} \gamma_{i j t} \ln \bar{v}_{i r t} \ln \bar{v}_{j r t}
$$

In the end, we note that, since $\bar{u}_{i c t}=\sum_{h=1}^{N_{c t}} \widehat{\theta}_{h c t} u_{i h t}$, we have $E \bar{u}_{i c t}=0$ and $V\left(\bar{u}_{i c t}\right)=$ $\sum_{h=1}^{N_{c t}} E \widehat{\theta}_{h c t}^{2} V\left(u_{i h t}\right)$. 


\section{Estimation of the Aggregated Model}

The aggregated AI demand system is estimated using the iterated least squares estimator developed by Blundell and Robin (1999). This amounts to iterating a series of ordinary least squares regressions until convergence on the parameters is reached. Within each iteration, the estimation is performed equation by equation while imposing the constraints of additivity, homogeneity, and symmetry. Therefore, in the present study, in contrast to Blundell and Robin's approach, the symmetry constraint is directly imposed. ${ }^{6}$

The main problems in the estimation step are bias and heteroscedasticity, both of which result from the use of estimated variables instead of the true variables, as well as the potential endogeneity of total household food expenditure, as stressed by Blundell and Robin (1999), and Lecocq and Robin (2006). These problems are solved as follows:

(1) Induced bias: Estimating budget shares and expenditure causes a bias problem, but its is negligible as we highlight just below. Recall that $\widetilde{w}_{i c t}=\sum_{h=1}^{N_{c t}} \widehat{\theta}_{h c t} w_{i h t}$ is unknown and is replaced by the predictor $\widehat{w}_{i c t}$. More precisely, if we define $\varepsilon_{i h t}^{(2)}=\widehat{w}_{i h t}-w_{i h t}$, we get over each cell $\widetilde{w}_{i c t}=\widehat{w}_{i c t}-\overline{\varepsilon_{i c t}^{(2)}}$, where $\overline{\varepsilon_{i c t}^{(2)}}=\sum_{h=1}^{N_{c t}} \widehat{\theta}_{h c t} \varepsilon_{i h t}^{(2)}$. This creates a bias term-as well as an additional source of heteroscedasticity (see below) — that can be approximated to the first order (see the online appendix) by

(6) $\quad E \varepsilon_{i h t}^{(2)} \approx\left\{\begin{array}{r}\theta_{h c t} N_{i c t}^{-1}\left[\sum_{j: h \in \mathscr{P}(j)^{c} \cap H} \omega_{i, j, t}\right], \text { if } h \in \mathscr{P}(i) \cap H_{c t} \\ x_{c t}^{-2} \sum_{h \in \mathscr{P}(i)^{c}} \theta_{h c t} N_{i c t}^{-1}\left[\sum_{j: h^{\prime} \in \mathscr{P}(j)^{c} \cap H_{c t}} \frac{1}{N_{j c t}} \omega_{i, j, t}+\sum_{j} \omega_{i, j, t}\right] \text { else }\end{array}\right.$

This bias is eventually negligible regarding the magnitude of $x_{c t}^{2}$, and we do not need to take it into account in the estimation.

(2) Heteroscedasticity: Due to the aggregation process, the new model becomes heteroscedastic. Notice that, if the $u_{i h t}$ is i.i.d., then the variance of the aggregated residual is $V\left(\bar{u}_{i c t}\right)=V\left(u_{i h t}\right) \sum_{h=1}^{N_{c t}} E \widehat{\theta}_{h c t}^{2}$. Since $\sum_{h=1}^{N_{c t}} \widehat{\theta}_{h c t}=1$, we have from the preceding computations $E \widehat{\theta}_{h c t}=O\left(1 / N_{c t}\right)$ and $E \widehat{\theta}_{h c t}^{2}=O\left(1 / N_{c t}^{2}\right)$, so that $V\left(\bar{u}_{i c t}\right)=O\left(1 / N_{c t}\right)$. In this case, it is possible to correct for most of the heteroscedasticity simply by multiplying 
each variable defined at the cell level by the square root of the size of the cell. However, if the residual can be decomposed into some fixed effects and a mixed effect, say $u_{i h t}=u_{i}^{*}+u_{t}^{*}+u_{i t}^{*}+u_{i h t}^{*}$, where the components are centered and independent, then, by aggregation, we get $\bar{u}_{i c t}=u_{i}^{*}+u_{t}^{*}+u_{i t}^{*}+\sum_{h=1}^{N_{c t}} \widehat{\theta}_{h c t} u_{i h t}^{*}$ with $V\left(\sum_{h=1}^{N_{c t}} \widehat{\theta}_{h c t} u_{i h t}^{*}\right)=O\left(1 / N_{c t}\right)$ and fixed variances for the other components. In addition, it is also worth noting that $\overline{\varepsilon_{i c t}^{(2)}}$, the error introduced by using predictors instead of the true values, may be interpreted precisely as a cross effect of the form $u_{i t}^{*}$. It follows that, if the products and temporal effects are large, then the heteroscedasticity should not be corrected by multiplying the equations by $\sqrt{N_{c t}}$ because this would lead to even greater heteroscedasticity. In these circumstances, for reasons that are unclear, the aggregation process tends to reduce the variance inside the cell (the intravariance), but the imputation process tends to increase the variance of the predictor of the total household food expenditure and, therefore, of the shares. Since we want to obtain robust estimates, we will essentially use standard two-step methods and generalized least square estimators to correct for the heteroscedasticity.

(3) Endogeneity of total household food expenditure: The log total household foodexpenditure variable $\overline{\ln x}_{c t}$ and regression residuals $\bar{u}_{c t}$ may be correlated for at least one of the following two reasons: First, either because of simultaneity of the determination of total household food expenditure and budget shares, since common shocks may determine both taste and total household food-expenditure changes, and/or second, because of unobserved heterogeneity. Following Blundell and Robin (1999), the first likely source of correlation is usually controlled for by means of instrumental variable techniques, using income as an instrument for total household food expenditure. In particular, we augment the AI demand system specification with the residuals $v_{c t}$ of the regression of the total household food expenditure $\overline{\ln x}_{c t}$ on sociodemographic variables $\bar{Z}_{c t}$, prices $\ln \bar{v}_{i r t}$, and the logged income of cohort $c$ at period $t$, denoted by $\overline{\ln y_{c t}}=\sum_{h=1}^{N_{c t}} \widehat{\theta}_{h c t} \ln y_{h t}$.

The second likely source of correlation is corrected as in Lecocq and Robin (2006). Following Mundlak (1978), they show that unobserved heterogeneity can be fully taken into account by integrating the means of the log of income and the log total house- 
hold food expenditure for each cell $c$ in the set of sociodemographic variables $\bar{Z}_{c t}$, i.e., $\overline{\ln y_{c \bullet}}=\frac{1}{T} \sum_{t=1}^{T} \overline{\ln y_{c t}}$, and $\overline{\ln x_{c}}=\frac{1}{T} \sum_{t=1}^{T} \overline{\ln x}_{c t}$, respectively. Testing for the absence of $\overline{\ln y_{c \bullet}}$, and $\overline{\ln x_{c \bullet}}$ in the regressions allows direct testing to detect biases due to unobserved heterogeneity.

Finally, we estimate the following aggregated AI demand system over cells, in region $r$

$$
\widehat{w}_{i c t}=\alpha_{i 0}+\bar{Z}_{c, t}^{*} \alpha_{i}+\sum_{j=1}^{N} \gamma_{i j} \ln \bar{v}_{j r t}+\beta_{i}\left(\overline{\ln x}_{c t}-\overline{\ln \left(a\left(v_{r t}\right)\right)}\right)+\bar{u}_{i c t}
$$

$\bar{Z}_{c t}^{*}$ is composed of two sets of variables: (i) one that contains the variables $v_{c t}, \overline{\ln y_{c \bullet}}$, and $\overline{\ln x_{c} \bullet}$ to correct the likely endogeneity of total household food expenditure, and (ii) a set of sociodemographic factors that may influence consumer food choices. Sociodemographic variables include the education level of principal earner (no diploma, low degree of diploma, level of bac, bac, and higher degree); urbanization (rural town, small city less than 10,000 inhabitants, city less than 50,000 inhabitants, city less than 200,000 inhabitants, big city, and Paris and its suburbs); the proportion of households in the cell that have a garden, a cellar, and home ownership; and age ranges of children in the household $\left(0-5,6-10,11-15\right.$, and 16-18). ${ }^{7}$ We also include the proportion of households in the cell that have at least one child younger than 18. Finally, four-week and annual dummies are introduced in the model. Table 2 displays some descriptive statistics for these variables. These variables are then aggregated over cohorts.

\section{Estimation and Elasticities}

\section{Estimation of the AI Demand System}

Table 3 presents some descriptive statistics for expenditure shares and unit values in French francs per kilogram (1 euro was taken to equal 6.55957 French francs). Table 3 also displays the standard errors of the regressions, denoted by RMSE. The close correspondence between simulated values and sample observations indicates that our estimated AI demand system is reliable for use in estimating demand elasticities. The goodness-offit appears to be satisfactory in the standard of analyzing household survey data, with $R^{2}$ 
value in a range of 0.82 to 0.24 . In addition, biases due to unobserved heterogeneity are detected. Table 3 shows that $\overline{\ln x_{c} \bullet}$ is significant for all food items except red meat, cooked meat, eggs, potatoes, fruit juices, dried fruits, processed vegetables, cheese/butter/cream, soft drinks, and water; and $\overline{\ln y_{c} \bullet}$ is significant for all groups except fish, eggs, potatoes, processed fruits and vegetables, fruit juices, and alcohol. As Lecocq and Robin (2006) also suggest, these results show that the usual instrumentation by income, proposed by Blundell and Robin (1999), is not sufficient on its own to control fully for the endogeneity of total food expenditure in the AI demand system.

Given the number of food categories, and the large number of sociodemographic variables, the coefficient estimates are not reported here, but they are available in the online appendix. We found that the higher the education level of the head of the household, the more the food budget will be allocated to fresh vegetables and fruits, milk products, cheese/butter/cream, and the less it will be allocated to meat, cooked meat, and alcohol. Having a child younger than 18 contributes significantly to increased purchasing of meat, dairy products, prepared meals, cheese/butter/cream, sugar-fat products, and soft drinks, but to decreased purchasing of fish, fresh fruits and vegetables, and alcoholic beverages. However, if we focus our attention on households with children aged $0-5$, our estimates showed that significantly more of the food budget will be allocated to fresh fruits and fish, and less to meat and cheese/butter/cream.

\section{Demand Elasticities}

Following the approach of Banks, Blundell, and Lewbel (1997), we calculate uncompensated price elasticity matrix $D_{c}=\left[e_{i j, c, t}\right]_{1 \leq i, j \leq N}$, such that the price elasticity of demand for food category $i$ with respect to price $j$ is $e_{i j, c, t}=-l_{i j}+$ $\widehat{w}_{i c t}^{-1}\left[\gamma_{i j}-\beta_{i}\left(\mu_{i c}+\sum_{j=1}^{n} \gamma_{i j} \ln \bar{v}_{j r t}\right)\right]$, where $\iota_{i j}$ equals one when $i=j$ and zero otherwise for $i, j=1, \ldots, N, \mu_{i c}=\alpha_{i 0}+\bar{Z}_{c, t}^{*} \alpha_{i}$ and for a cell $c=1, \ldots, C$ in region $r=1, \ldots, R$. The elasticities are calculated using the average estimated shares and the mean point of the other variables for each income class. Total expenditure elasticities are reported in the 
online appendix. To save space, table 4 reports the estimated own- and cross-price elasticities for selected food categories across income class that will be useful later; it gives the percentage of change in quantities purchased for the 22 food categories by modifying the prices of fresh fruits and vegetables, fruit juices, milk products, cheese/butter/cream, prepared meals, sugar-fat products, and soft drinks by $1 \%$. Results are fully reported in the online appendix. In the latter, we show that all of the own-price elasticities are negative, except for alcohol for modest households, and almost all are significant and below one, except for red meat, fish, dried fruits, prepared meals, salt-fat products, and water. Furthermore, own-price elasticities for grain products, fruits, fruit juices, vegetables, and milk products are comparable to those reported by Huang (1996). We also found that modest households are significantly more sensitive than well-off households to own-price change for fish, dried fruits, milk products, cheese/butter/cream, oils, sugar-fat products, and mineral and spring waters but less sensitive for fresh vegetables and fruits and alcohol. Table 4 shows substantial disparities across income class for fresh vegetable and fruit own-price effects, as Bertail and Caillavet (2008) also found, while we get no disparity across income class for own-price effects of fruit juices. Another insightful result is that decreasing the fresh vegetable price strongly decreases potato purchases and to a lesser extent salt-fat product purchases. Note also that increasing the soft drink price brings about a fall in potato, prepared meal, and salt-fat product purchases. This result is interesting because sodas are generally drunk while eating these products. We found that the increase in the soft drink price benefits fruit juice purchases. These results may give some argument in favor of a tax on other soft drinks, as Jacobson and Brownell (2000) proposed; however, the levels of the corresponding price elasticities are quite weak. More comments are given in the online appendix.

\section{Nutrient Elasticities}

The nutrient elasticities are calculated following the approach of Huang (1996) and using the demand elasticities calculated above. Huang shows that combining demand elasticities 
with the values of the nutrient shares of each composite good category, the $L$ nutrient elasticities with respect to good prices and total food expenditure can simply be calculated as $N u t_{c}=S_{c} * D_{c}$ where $N u t_{c}$ stands for the $(L \times N)$ matrix of nutrient elasticities, and $S_{c}=\left[S_{l i, c}\right]_{\substack{1 \leq l \leq L \\ 1 \leq i \leq N}}$ is the $(L \times N)$ matrix of the food's share of the $L$ nutrients, where $S_{l i, c}$ represents the $i$ th food's contribution to the $l$ th nutrient, so that $\sum_{i=1}^{N} S_{l i, c}=1$, for a cell $c=1, \ldots, C . N u t_{c}$ shows the effects on $L$ nutrients in response to changes in $N$ food prices for a particular cell $c$. The result is that a change in a particular food price will affect all food quantities demanded through the interdependent demand relationships and thus cause a simultaneous change in the levels of nutrient availability. The online appendix gives details on the construction of $S_{c}$.

The crucial finding was that nutrient price elasticities are inelastic, as Huang and Lin (2000) and Beatty and LaFrance (2005) also found. Here, in table 5, to save space, we display only energy, saturated and polyunsaturated fat, sodium, calcium, beta-carotene, vitamin $\mathrm{C}$, and magnesium elasticities for the 22 food categories across income class. All of the nutrient elasticity values can be found in the online appendix. As shown in table 5, decreasing total energy purchased involves reducing the price of all food, except fish. Another interesting point is that we estimated disparities in energy elasticities across income class for the majority of food categories. In particular, for sugar-fat products, we found that energy elasticity is $34 \%$ higher for modest households than for well-off households. We also found that energy purchased for well-off households is particularly sensitive to changes in the price of prepared meals and cheese/butter/cream, whereas modest households are sensitive to changes in the price of prepared meals and sugar-fat products. Table 5 displays disparities across income class for saturated-fat elasticities. Again, this disparity is particularly noticeable for sugar-fat products. We also estimated that saturated fat purchased falls by decreasing the price of the other meat category, which is characterized by a lower saturated-fat content than red meats. Increasing cheese/butter/cream and sugar-fat product prices also reduces households' purchases in saturated fat, and at the 
same time increases their purchases in polyunsaturated fat. A detailed discussion of the trade-offs between the nutrients is provided in the next section.

\section{Simulation of a Fat Tax}

In this section we examine whether a fat-tax policy can alter French households' purchases of calories, as well as the consequences of such a policy on the purchases of other nutrients. As Chouinard et al. (2007) point out, the assessment of the impact of a fattax policy is relevant only if we assume that it is fully passed on to consumers in prices and that the food industry and retailers make no other responses. Our examination will therefore represent the maximum impact of the tax. The fat tax considered in this article consists, as French State policy makers recently proposed (IGF-IGAS, 2008), in increasing the value added tax (VAT) of the targeted food categories by $\tau$. Following Nichèle and Robin (1995), the new price of food item $i$ after the implementation of the fat tax is now equal to $\bar{v}_{i r, 1}=\left(1+\frac{\tau}{1+V A T}\right) \bar{v}_{i r, 0}$, where $\bar{v}_{i r, 0}$ stands for the pre-tax price. ${ }^{8}$ The VAT rate is assumed, for simplicity's sake, to be equal to $5.5 \%$ for all food items, except for alcohol, which is equal to $19.6 \% .^{9}$ The fat tax impact was appraised by calculating (1) the implied percentage of change in nutrient quantities purchased, and the short- and long-run effect on body weight, (2) the implied level of revenue raised per household and at the national level, and (3) the short-run welfare cost. Below, all the quantitative effects are calculated at the average point over time for an increase of targeted food category prices by $\frac{\tau}{1+V A T}=10 \%$.

\section{Which food categories should be taxed to reduce energy purchased?}

Taxing all food products high in energy is of course politically unrealistic. We must, therefore, determine which food category (or categories) to tax to have the highest impact on calories purchased. We have two ways of answering this question. First, we can analyze the contribution of each of the 22 food categories to total energy, and, second, the corresponding nutrient elasticities. The first analysis reveals interesting differences in the sources of energy across income and may, therefore, provide insightful information to 
food-policy makers. Each food category's share of the 32 nutrients can be found in the online appendix. We noted interesting disparities in the main sources of energy purchased across income groups. In particular, for well-off households, the food with the highest share of energy is the cheese/butter/cream category, which provides $14.94 \%$ of total energy purchased, compared to $14.02 \%$ for modest households. For modest households, the category with the highest share of energy is sugar-fat products, accounting for $16.86 \%$ of total energy purchased, compared to $13.56 \%$ for well-off households.

The analysis of energy elasticities given in the previous section provides further support to the previous analysis, and additional information. Indeed, table 5 shows that if we want to reduce the total energy that households purchase, the most efficient (less than $-0.10 \%$ ) way to do so is to increase prices of prepared meals, cheese/butter/cream, and sugar-fat products. Modifying cooked meat price could be relevant also.

Ultimately, as we see from the two previous analyses, taxing cheese/butter/cream, sugar-fat products, and prepared meals will have the greatest impact on households' total energy purchased. An additional effect of taxing these food categories is that they are the main sources of saturated fats purchased.

\section{The Effects of a Fat Tax}

Marshall (2000) and Mytton et al. (2007) assessed the effects of imposing a tax on cheese/butter/cream and sugar-fat products on nutrients purchased in Great Britain. Chouinard et al. (2007) estimated the effects of a fat tax on dairy products in the U.S. But these studies focused attention on only a few nutrients (saturated fats for Marshall, poly-, mono- and unsaturated fats, cholesterol, and sodium for Mytton et al., and fats for Chouinard et al.). For France, Bonnet, Dubois, and Orozco (2008) simulated the impact of a fat tax on calories, protein, lipids, and carbohydrates purchased by estimating the price elasticity of BMI. To the best of our knowledge, the present study is the most complete assessment that has been carried out in France. 
(1) Impact on nutrients purchased. Given how nutrient elasticities are constructed, the percentage of quantity change in nutrient $l$, caused by a price variation in food category $i$, is equal to $\frac{\tau}{1+V A T} N u t_{l i, c}$. If the tax affects a subset $I$ of food categories, or in other words, if the reader would like to assess the percentage of change brought about by a tax on several food categories, then the latter value is equal to $\frac{\tau}{1+V A T} \sum_{i \in I} N u t_{l i, c}$. Note also that change is proportional to the price increase. Table 6 reports the percentage of quantity change in total nutrients purchased for modest and well-off households if cheese/butter/cream, sugar-fat-product, and/or prepared-meal prices increase by $10 \%$, over a four-week period. Two major results can be underlined. First, taxing these food categories decreases total energy, as targeted. This is mainly due to a fall of fats purchased, especially saturated fat. At first glance this result could seem to be a mechanical effect or quite intuitive. However, the effects of a fat tax on nutrients purchased is difficult to predict given that food purchases are highly interdependent; taxing food to reduce total calories purchased could lead to the opposite effect as a result of cross-price elasticities, as illustrated by Mytton et al. (2007) in the case of a tax in the U.K. based on foods high in saturated fat and by Schroeter, Lusk, and Tyner (2008) in the case of a tax in the U.S. based on food consumed away from home. Furthermore, the magnitude of the effects of a tax based on the three food categories is comparable to that reported by Mytton et al. (2007) for their best outcome: they found that extending the VAT to food items high in saturated fat (their "best outcome") leads to a percentage of change in energy purchased equal to $-6.1 \%$ (we found 6.0 and $6.4 \%$ for well-off and modest households, if we set $\frac{\tau}{1+V A T}=17.5 \%$ ). Second, we found, as expected in light of the nutrient elasticity disparities described above, that a tax on sugar-fat products has quite different impacts on total nutrients purchased depending on income class. In particular, we assessed that a $10 \%$ increase in the price of sugar-fat products decreases household total energy purchased by $0.79 \%$ for well-off versus $1.20 \%$ for modest households.

If we turn to the results in detail, table 6 shows that taxing prepared meals has the highest effect on total energy purchased. This tax leads to additional nutritionally beneficial 
effects for sodium, retinol or vitamin A (mainly found in fruits and vegetables), betacarotene (which is consistent with the result that prepared meals and fresh vegetables are substitutes, see table 4), and vitamin D (mainly found in fish, and so consistent with table 4). However, these positive effects are at the expense of vegetal protein, polyunsaturated and monounsaturated fat, and vitamins B1, B6, and E. Table 6 shows that taxing the cheese/butter/cream category has the second highest impact on calories purchased for well-off households, while for modest households it is taxing sugar-fat products. A very appealing effect of taxing these two food categories is that the percentage drops in saturated fat and cholesterol are among the highest falls. Another outstanding result is that, in contrast to taxing prepared meals, taxing these two food categories increases the polyunsaturated fat purchased, especially for well-off households. This is consistent with the result displayed in table 4, which shows that cheese/butter/cream (sugar-fat products) and oils are substitutes. As with prepared meals, taxing these two food categories reduced sodium, but to a lesser extent. Interestingly, for modest households, the strongest decrease in sodium resulted from taxing sugar-fat products, while for well-off households it is from taxing cheese/butter/cream. Taxing cheese/butter/cream also resulted in a positive effect on purchases of beta-carotene and vitamin E (found mainly in oils). However, these positive effects were offset by a negative effect on purchases of all other vitamins, calcium, magnesium, potassium, and phosphorus.

Although it is hard to assess the effects of these taxes on health, we can approximate their effects on weight in the short and long run based on a biological model proposed by Kozusko (2001), which defines the body weight dynamic. The details of calculation and results for different types of consumers (classified by gender, age, and lifestyle) are given in the online appendix. We estimated, based on the average family size in France of 2.3, that increasing the price of cheese/butter/cream (prepared meals; sugar-fat products) by $10 \%$ would reduce total calories purchased by an individual, living in a well-off or modest household, on average to 16.65 and 17.58 (19.30 and 19.25; 10.69 and 18.02) calories per day, respectively. The estimated effects are quite small, but if this decrease is persistent, 
we found, using calibrated values for the basal metabolic rate and physical activity provided by UNU, WHO, and FAO (United Nations University, World Health Organization, Food and Agriculture Organization of the United Nations 2004), that this weak caloric variation would have an impact on weight in the long run. For example, let's assume a male between 30 and 60 years old, with a weight of $70 \mathrm{~kg}$, a light-activity lifestyle, belonging to a well-off household, whose total energy expenditure equals calorie intake before the implementation of a $10 \%$ tax on prepared meals. Following the implementation of this tax, his weight would decrease by $56 \mathrm{~g}$ after one month, $559 \mathrm{~g}$ after one year, and after seven years and six months he would weigh $68.9 \mathrm{~kg}$. Taxing all three of the targeted food categories would decrease the body mass of the same consumer by $136 \mathrm{~g}$ after one month, $1.351 \mathrm{~kg}$ after one year, and finally, almost nine years after implementation of the fat tax, he would weigh $67.3 \mathrm{~kg}$. We wonder whether consumers would be patient enough to benefit from these long-term health effects, given that they would feel worse off in the short run, since they would consume less without immediate substantial effects on their weight. Etilé (2008), who estimated the price-BMI relationship in France, found comparable long-term effects of a fat tax on body weight.

(2) Impact on revenue raised. Simple calculations shows that if the VAT of the food category $i$ is increased by $\tau$, the average tax revenues raised are equal to $R_{c}=\sum_{k=1}^{N} R_{k c}$, for cohort $c$, where $R_{i c}=\left(\frac{V A T+\tau}{1+V A T+\tau}\right) \bar{Q}_{i c, 1} \bar{v}_{i r, 1}$ and $R_{j c}=\left(\frac{V A T}{1+V A T}\right) \bar{Q}_{j c, 1} \bar{v}_{j r}$ for $i \neq j$, and $\bar{Q}_{i c, 1}=$ $\left(1+\frac{\tau e_{i i, c}}{1+V A T}\right) \bar{Q}_{i c, 0}$, and $\bar{Q}_{j c, 1}=\left(1+\frac{\tau e_{j i, c}}{1+V A T}\right) \bar{Q}_{j c, 0}$ of food categories $i$ and $j$ purchased. Despite the small impact on nutrient purchases, we found quite a substantial boost in tax revenue: a $10 \%$ raise (or equivalently $\tau=0.1055$ ) in the price of cheese/butter/cream (prepared meals; sugar-fat products) brings about an increase of tax revenues equal on average to $€ 1.80(€ 1.07 ; € 1.60)$ and $€ 1.86(€ 1.09$; $€ 2.15)$ per household and four-week period for well-off and modest households, respectively. The corresponding additional national tax revenues, calculated for the average household, are $€ 45.64$ million ( $€ 25.96$ million; $€ 45.55$ million), given that the 1999 census counted 23.8 million households in France. To demonstrate the importance of these fat taxes on revenue, we calculated the 
percentage increase in tax revenue when France goes from an economy without fat tax to an economy with a $10 \%$ fat tax. We found that government revenue increases by $16.3 \%$, $9.26 \%$, and $16.59 \%$, respectively. These substantial effects are due to highly inelastic price elasticities. If the tax is implemented over the three targeted food categories, the government gets additional tax revenues equal to $€ 4.31$ and $€ 4.96$ per household and four-week period from well-off and modest households, respectively.

(3) Impact on short-run welfare. The short-run welfare cost is defined as the fall in total household food expenditures that a household living in an environment with no tax is willing to accept while remaining indifferent to living in an environment with a tax. This definition means that the welfare assessment does not include the long-term effects of the tax on household physical health. Its measurement for the aggregated AI demand system is presented in the online appendix. We estimated that modest and well-off households would be willing to accept on average a total household food-expenditure reduction of $€ 2.27$ (€1.38; €1.28) and €2.30 (€1.41; €4.33) per four-week period, respectively, instead of facing a $10 \%$ tax on cheese/butter/cream (prepared meals; sugar-fat products). So, first, welfare costs vary greatly across income levels when sugar-fat products are taxed. Second, they are higher than the tax revenue for cheese/butter/cream and prepared meals, and, especially for modest households, for sugar-fat products. At the national level, we found that the welfare costs of taxing cheese/butter/cream (prepared meals; sugar-fat products), calculated for the average household, are equal to $€ 57.36$ million ( $€ 33.45$ million; $€ 39.51$ million).

How regressive are these fat taxes? We assessed that the regulatory burdens (defined as the four-week equivalent variation of a household's four-week income ratio) of a tax based on cheese/butter/cream (prepared meals; sugar-fat products) are equal, on average, to $0.068 \%(0.041 \% ; 0.038 \%)$ for well-off households, $0.11 \%(0.058 \% ; 0.068 \%)$ for average upper households, $0.15 \%(0.083 \% ; 0.11 \%)$ for average lower households, and $0.22 \%$ $(0.14 \% ; 0.42 \%)$ for modest households. Like Chouinard et al. (2007), we found that 
this kind of political instrument used to modify households' nutrients purchased can be extremely regressive, as illustrated for sugar-fat products.

\section{Discussion}

This study questioned the relevance and efficacy of a fat-tax policy in influencing households' nutrients purchased by estimating a complete food demand model. We developed a cohort model by aggregating an AI demand system over cohorts, and we precisely analyzed how the aggregation process affected estimations in terms of bias and heteroscedasticity. As the number of data sources available to researchers increases, the cohort method developed here may be especially useful for combining information obtained from two or more samples drawn from the population. It should be particularly helpful when there is no single sample that contains all relevant variables, as when economists want to combine administrative datasets.

Our general approach was applied to the French subpanels of the TNS Worldpanel for the period 1996-2001. We showed that price elasticities and the resulting nutrient elasticities are inelastic, and so we concluded that a fat-tax policy is unsuitable for substantially affecting the nutrients purchased by French households, and leads to ambiguous effects. Furthermore, although it would generate a large tax revenue, the fat tax is extremely regressive.

All assessments of fat-tax policy so far have assumed a fixed set of food products, thereby excluding the possibility of changes in the food industry in response. If a tax is implemented, how would the food industry hedge the tax? Two strategies are possible. First, the food industry might change the nutritional quality of the taxed products to smooth retail prices and avoid a decrease in sales. Second, the industry might modify the composition of the taxed products by substituting more expensive components and/or implementing new industrial production processes, thereby making the innovative product less affordable for modest households. These likely strategies would aggravate socioeconomic disparities in the nutritional quality of food selection and could have major 
implications for health, given that nutrition is related to the development of certain chronic diseases. Thus, food policy makers need to keep in mind that a fat-tax policy might have perverse effects insofar as it could exacerbate nutritional disparities among consumers.

Finally, given the small and ambiguous impact the fat tax has on nutrients purchased, its regressive nature, and its likely perverse effects, we wonder whether it might not be more effective to hold it out as a threat to spur the food industry to voluntarily reduce calories via a decrease in saturated-fat content in food products. We calculate that if saturated fat in the cheese/butter/cream category were voluntarily reduced by $1 \%$, saturated fat purchases would fall on average by $0.39 \%$ per household per four-week period, all else equal (particularly prices ${ }^{10}$ and average quantities purchased), versus $0.17 \%$ if the prices of items in the cheese/butter/cream category were raised by $1 \%$. The twin goals of a fat-tax policy are to decrease the sale and consumption of unhealthful foods, and to raise revenue aimed at supporting programs to improve diet and prevent obesity. Based on our findings, we believe that, for the first goal, the threat of imposing a fat tax may well be more beneficial for French consumers than the actual imposition of one; and for the second goal, although such a tax does indeed raise substantial revenues, it is unacceptably regressive. 
Notes

${ }^{1}$ Taxing food to reduce total calories purchased could lead to the opposite effect as a result of cross-price elasticities, as illustrated by Mytton et al. (2007) and Schroeter, Lusk, and Tyner (2008).

${ }^{2}$ Another quite stimulating alternative is the discrete choice demand model proposed by Griffith and Nesheim (2008).

${ }^{3}$ The first program was implemented in 2001. Chern and Rickertsen (2003) provide interesting articles on the impact of health information on food demand.

${ }^{4}$ However, in some cases, an incomplete system provides a relevant approximation for assessing the global effects of a tax on a specific group of products on particular nutrients purchased, as shown by Chouinard et al. (2007) in the case of the impact of a tax based on dairy products on U.S. households' fat purchases.

5 Another advantage of considering cohorts of households is that we never observe null mean purchase for the categories of products considered.

${ }^{6}$ In Blundell and Robin (1999), the symmetric restricted parameters are obtained in the second step of the estimation using a minimum distance estimator.

${ }^{7}$ The reference modality for each socioeconomic variable is in italics.

${ }^{8}$ VAT is imposed on all food items in France and is a fixed proportional addition to the producer price $\widetilde{v}_{i r}$, such that $\bar{v}_{i r, 0}=(1+V A T) \widetilde{v}_{i r}$.

${ }^{9} \mathrm{~A}$ VAT of $19.6 \%$ is actually charged on sweets, margarine, vegetable fats, caviar, and certain kinds of chocolate (milk, hazelnut, and white) in France.

${ }^{10}$ Constant prices are not so unrealistic regarding the assumed weak reduction in saturated fat. 


\section{References}

Allais, O., and J. Tressou. 2008. "Using Decomposed Household Food Acquisitions as Inputs of a Kinetic Dietary Exposure Model.” Statistical Modelling 8:in press.

Alston, J., J. Chalfant, and N. Piggott. 2001. "Incorporating Demand Shifters in the Almost Ideal Demand System.” Economics Letters 70:73-78.

Banks, J., R. Blundell, and A. Lewbel. 1997. "Quadratic Engel Curves and Consumer Demand." The Review of Economics and Statistics 79:527-539.

Beatty, T., and J. LaFrance. 2005. "United States Demand for Food and Nutrition in the Twentieth Century." American Journal of Agricultural Economics 87:1159-1166.

Bertail, P., and F. Caillavet. 2008. "Fruit and Vegetables Consumption Patterns: A Segmentation Approach.” American Journal of Agricultural Economics 90:827-842.

Blundell, R., and J. Robin. 1999. "Estimation in Large and Disaggregated Demand Systems: An Estimator for Conditionally Linear Systems." Journal of Applied Econometrics 14:209-232.

Bonnet, C., P. Dubois, and V. Orozco. 2008. "Food Consumption and Obesity in France." Paper presented at INRA-IDEI Workshop on Economics of Obesity, Toulouse, 12-13 December.

Chern, W., and K. Rickertsen. 2003. Health, Nutrition and Food Demand. Wallingford, Oxon: CABI Publishing.

Chesher, A. 1997. "Diet Revealed?: Semiparametric Estimation of Nutrient Intake-Age Relationships." Journal of the Royal Statistical Society A 160:389-428.

Chouinard, H., D. Davis, J. LaFrance, and J. Perloff. 2007. "Fat Taxes: Big Money for Small Change." Forum for Health Economics and Policy 10: Iss. 2 (Obesity), Article 2. http://www.bepress.com/fhep/10/2/2.

Deaton, A. 1985. "Panel Data from Time Series of Cross-Sections.” Journal of Econometrics 30:109-126.

Deaton, A., and J. Muellbauer. 1980. “An Almost Ideal Demand System.” The American Economic Review 70:312-326. 
Detournay, B., F. Fagnani, M. Phillippo, C. Pribil, M. Charles, C. Sermet, A. Basdevant, and E. Eschwège. 2000. "Obesity Morbidity and Health Care Costs in France: An Analysis of the 1991-1992 Medical Care Household Survey.” International Journal of Obesity 24:151-155.

Etilé, F. 2008. "Food Price Policies and the Distribution of Body Mass Index: The French Case." Mimeo Paris Shcool of Economics N 2008 - 28.

Favier, J., J. Ireland-Ripert, C. Toque, and M. Feinberg. 1995. REpertoire Général des Aliments (REGAL): Tables de Composition. Paris: INRA editions, CNEVA-CIQUAL.

Gardes, F., G. Duncan, P. Gaubert, M. Gurgand, and C. Starzec. 2005. "Panel and PseudoPanel Estimation of Cross-Sectional and Time Series Elasticities of Food Consumption: The Case of US and Polish Data.” Journal of Business \& Economic Statistics 23:242254.

Griffith, R., and L. Nesheim. 2008. "Empirical Estimates of the Impact of a Fat Tax." Paper presented at INRA-IDEI Workshop on Economics of Obesity, Toulouse, 12-13 December.

Huang, K. 1996. "Nutrient Elasticities in a Complete Food Demand System." American Journal of Agricultural Economics 78:21-29.

Huang, K., and B. Lin. 2000. "Estimation of Food Demand and Nutrient Elasticities from Household Survey Data.” USDA, ERS, Technical Bulletin No. 1887.

Inspection Générale des Finances-Inspection Générale des Affaires Sociales (IGF-IGAS). 2008. Rapport sur la Pertinence et la Faisabilité d'une Taxe Nutritionnelle. Paris: La Documentation Française.

Jacobson, M., and K. Brownell. 2000. "Small Taxes on Soft Drinks and Snack Foods to Promote Health.” American Journal of Public Health 90:854-857.

Kozusko, F. 2001. "Body Weight Setpoint, Metabolic Adaption and Human Starvation." Bulletin of Mathematical Biology 63:393-403.

Kuchler, F., E. Golan, J. Variyam, and S. Crutchfield. 2005. "Obesity Policy and the Law of Unintended Consequences." Amber Waves 3:26-33. 
Kuchler, F., A. Tegene, and J. Harris. 2005. “Taxing Snack Foods: Manipulating Diet Quality or Financing Information Programs?” Review of Agricultural Economics 27:420.

LaFrance, J. 1990. "Incomplete Demand Systems and Semilogarithmic Demand Models." Australian Journal of Agricultural Economics 34:118-131.

LaFrance, J., T. Beatty, R. Pope, and G. Agnew. 2002. "Information Theoretic Measures of the U.S. Income Distribution in Food Demand.” Journal of Econometrics 107:235257.

LaFrance, J., and W. Hanemann. 1989. “The Dual Structure of Incomplete Demand Systems." American Journal of Agricultural Economics 71:262-274.

Lecocq, S., and J. Robin. 2006. "Estimating Demand Response with Panel Data." Empirical Economics 31:1043-1060.

Levy, E., P. Levy, C. Le Pen, and A. Basdevant. 1995. "The Economic Cost of Obesity: The French Situation.” International Journal of Obesity 19:788-792.

Marshall, T. 2000. "Exploring a Fiscal Food Policy: The Case of Diet and Ischaemic Heart Disease.” British Medical Journal 320:301-305.

Mundlak, Y. 1978. "On the Pooling of Time Series and Cross Section Data." Econometrica 46:69-85.

Mytton, O., A. Gray, M. Rayner, and H. Rutter. 2007. "Could Targeted Food Taxes Improve Health?" Journal of Epidemiology and Community Health 61:689-694.

Nichèle, V., and J. Robin. 1995. "Simulation of Indirect Tax Reforms Using Pooled Micro and Macro French Data.” Journal of Public Economics 56:225-244.

Paraponaris, A., B. Saliba, and B. Ventelou. 2005. “Obesity, Weight Status and Employability: Empirical Evidence from a French National Survey." Economics and Human Biology 3:241-258.

Park, J.L., and O. Capps. 1997. "Demand for Prepared Meals by U.S. Households.” American Journal of Agricultural Economics 79:814-824. 
Schroeter, C., J. Lusk, and W. Tyner. 2008. "Determining the Impact of Food Price and Income Changes on Body Weight.” Journal of Health Economics 27:45-68.

United Nations University, World Health Organization, Food and Agriculture Organization of the United Nations. 2004. Human Energy Requirements. FAO Food and Nutrition Technical Report Series 1.

World Health Organization. 2000. Obesity: Preventing and Managing the Global Epidemic. Report on a WHO Consultation Technical Report Series, No 894. 
Tables

Table 1. Descriptive Statistics of the Number of Households in Cells

\begin{tabular}{lccccc}
\hline \hline \multirow{2}{*}{$N_{c t}$} & Observations & Mean & Standard deviation & Min & Max \\
\cline { 2 - 6 } & 1872 & 208.12 & 132.97 & 59 & 634 \\
\hline \hline
\end{tabular}


Table 2. Proportion of Households for each Sociodemographic Variable

\begin{tabular}{lcc}
\hline \hline Sociodemographic variables & Mean & Standard error \\
\hline & & \\
Level of education of principal earner & & \\
No diploma & 0.159 & 0.180 \\
Low degree of diploma & 0.351 & 0.169 \\
Level of Bac & 0.176 & 0.093 \\
Bac and Higher degree & 0.314 & 0.253 \\
Urbanization & & \\
Rural town & & \\
Small city, pop. < 10,000 & 0.242 & 0.143 \\
City pop. $<$ 50,000 inhabitants & 0.120 & 0.070 \\
City pop. $<200,000$ inhabitants & 0.128 & 0.080 \\
Big city & 0.144 & 0.088 \\
Paris and its suburbs & 0.226 & 0.166 \\
Ages of children in household & 0.140 & 0.316 \\
Ages 0-5 & & \\
Ages 6-10 & & \\
Ages 11-15 & 0.181 & 0.252 \\
Ages 16-18 & 0.210 & 0.268 \\
Proportion of households with at least one child (<18) & 0.418 & 0.252 \\
Household attributes & & \\
Proportion of households with a garden & & \\
Proportion of households with a cellar & 0.248 & 0.171 \\
Proportion of home owners & 0.680 & 0.174 \\
& 0.749 & 0.115 \\
\hline \hline
\end{tabular}


Table 3. Sample Mean Shares and Unit Values (in French Francs per Kilogram, 1 euro $=6.55957$ French Francs), Estimation Summary Statistics, and Tests for Existing Biases Due to Unobserved Heterogeneity

\begin{tabular}{lcccccc}
\hline \hline & & & & & & \\
Food categories & Shares & Unit values & RMSE & $\mathrm{R}^{2}$ & $\overline{l n} x_{c \bullet}$ & $\overline{\ln y_{c}}$ \\
\hline Red meat & 0.068 & 62.713 & 0.011 & 0.433 & 0.021 & $0.010^{*}$ \\
Other meats & 0.085 & 39.767 & 0.010 & 0.426 & $0.044^{*}$ & $0.017^{*}$ \\
Cooked meats & 0.088 & 58.771 & 0.008 & 0.603 & 0.012 & $-0.015^{*}$ \\
Fish & 0.064 & 53.535 & 0.011 & 0.683 & $0.022^{*}$ & 0.005 \\
Eggs & 0.011 & 17.226 & 0.001 & 0.511 & -0.003 & -0.001 \\
Grain products & 0.023 & 13.839 & 0.002 & 0.729 & $-0.011^{*}$ & $-0.004^{*}$ \\
Potatoes & 0.009 & 5.743 & 0.003 & 0.241 & 0.001 & -0.001 \\
Fresh fruits & 0.062 & 10.766 & 0.010 & 0.708 & $-0.035^{*}$ & $0.012^{*}$ \\
Processed fruits & 0.005 & 16.083 & 0.001 & 0.334 & $-0.008^{*}$ & 0.000 \\
Fruit juices & 0.018 & 6.900 & 0.002 & 0.612 & 0.002 & -0.001 \\
Fresh vegetables & 0.050 & 11.300 & 0.008 & 0.696 & $0.032^{*}$ & $0.026^{*}$ \\
Processed vegetables & 0.019 & 16.978 & 0.002 & 0.685 & -0.000 & 0.001 \\
Dried fruits & 0.004 & 43.171 & 0.001 & 0.577 & 0.001 & $-0.003^{*}$ \\
Milk products & 0.085 & 9.404 & 0.006 & 0.774 & $-0.060^{*}$ & $-0.020^{*}$ \\
Cheese/butter/cream & 0.093 & 40.823 & 0.005 & 0.693 & -0.012 & $-0.010^{*}$ \\
Prepared meals & 0.060 & 34.263 & 0.009 & 0.442 & $-0.054^{*}$ & $0.014^{*}$ \\
Oils & 0.016 & 17.273 & 0.002 & 0.646 & $0.007^{*}$ & $-0.006^{*}$ \\
Salt-fat products & 0.010 & 43.748 & 0.001 & 0.534 & $0.006^{*}$ & $-0.006^{*}$ \\
Sugar-fat products & 0.096 & 37.653 & 0.007 & 0.822 & $-0.040^{*}$ & $-0.023^{*}$ \\
Soft drinks & 0.014 & 6.971 & 0.002 & 0.804 & -0.001 & $-0.010^{*}$ \\
Waters & 0.021 & 1.869 & 0.003 & 0.656 & -0.004 & $-0.004^{*}$ \\
Alcohol & 0.103 & 24.478 & 0.002 & 0.569 & $0.081^{*}$ & 0.019 \\
\hline \hline
\end{tabular}

Note: An asterisk shows that we can reject the null hypothesis that the bias is zero at the $5 \%$ level. 
Table 4. Price Elasticities Across Income Class

\begin{tabular}{|c|c|c|c|c|c|c|c|c|c|c|c|c|c|c|c|c|c|c|c|c|c|c|}
\hline & $\begin{array}{l}\text { Red } \\
\text { meat }\end{array}$ & $\begin{array}{l}\text { Other } \\
\text { meats }\end{array}$ & $\begin{array}{l}\text { Cooked } \\
\text { meats }\end{array}$ & Fish & 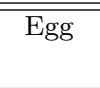 & " Grain $^{a}$ & Potato & $\begin{array}{l}\text { Fresh } \\
\text { fruits }\end{array}$ & $\begin{array}{l}\text { Pro }^{b} \\
\text { fruits }\end{array}$ & $\begin{array}{l}\text { Fruit } \\
\text { juice }\end{array}$ & $\begin{array}{l}\text { Fres }^{c} \\
\text { veget }\end{array}$ & $\begin{array}{l}\text { Pro }^{d} \\
\text { veget }\end{array}$ & $\begin{array}{l}\text { Dried } \\
\text { fruit }\end{array}$ & 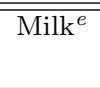 & $\overline{\text { Chee }^{f}}$ & $\begin{array}{l}\text { Pre }^{g} \\
\text { meal }\end{array}$ & "Oil & $\begin{array}{l}\text { Salt } \underline{h} \\
\text { fat }\end{array}$ & $\begin{array}{l}\text { Sug } \underline{i} \\
\text { fat }\end{array}$ & 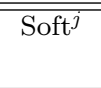 & Water & $\overline{\text { Alcohol }}$ \\
\hline \multicolumn{23}{|c|}{ Fresh fruits } \\
\hline Well-off & $.239^{*}$ & $-.158^{*}$ & -.048 & $-.250^{*}$ & -.084 & -.089 & -.052 & $-.355^{*}$ & -.231 & . 142 & -.025 & .041 & -.053 & -.048 & $-.121^{*}$ & .037 & -.093 & -.016 & $-.156^{*}$ & $.323^{*}$ & $.198^{*}$ & -.067 \\
\hline Avg upper ${ }^{k}$ & $.231^{*}$ & $-.143^{*}$ & -.044 & $-.288^{*}$ & -.073 & -.078 & -.044 & $-.234^{*}$ & -.208 & .140 & -.030 & .041 & -.075 & -.040 & $-.123^{*}$ & .053 & -.089 & -.024 & $-.134^{*}$ & $.247^{*}$ & $.203^{*}$ & -.089 \\
\hline Avg lower ${ }^{l}$ & $.232^{*}$ & $-.138^{*}$ & -.041 & $-.328^{*}$ & -.069 & -.069 & -.042 & -.118 & -.189 & .134 & -.038 & .040 & -.099 & -.035 & $-.122^{*}$ & .061 & -.086 & -.028 & $-.118^{*}$ & $.202^{*}$ & $.217^{*}$ & $-.107^{*}$ \\
\hline Modest & $.255^{*}$ & $-.146^{*}$ & -.041 & $-.360^{*}$ & -.067 & -.059 & -.042 & -.057 & -.184 & .134 & -.044 & .036 & -.104 & -.031 & $-.119^{*}$ & .058 & -.078 & -.027 & $-.104^{*}$ & $.165^{*}$ & $.245^{*}$ & $-.126^{*}$ \\
\hline \multicolumn{23}{|c|}{ Fruit juices } \\
\hline Well-off & .037 & -.008 & $-.087^{*}$ & -.040 & -.053 & $.169^{*}$ & $-.356^{*}$ & .023 & -.034 & $-.867^{*}$ & .012 & -.024 & .131 & .035 & -.018 & -.046 & .039 & .048 & $.054^{*}$ & $.255^{*}$ & .024 & $-.027^{*}$ \\
\hline Avg upper & .036 & -.007 & $-.079^{*}$ & -.045 & -.049 & $.156^{*}$ & $-.319^{*}$ & .027 & -.033 & $-.865^{*}$ & .013 & -.020 & .160 & .032 & -.018 & -.049 & .035 & .047 & $.048^{*}$ & $.198^{*}$ & .025 & $-.031^{*}$ \\
\hline Avg lower & .036 & -.007 & $-.074^{*}$ & -.051 & -.049 & $.143^{*}$ & $-.316^{*}$ & .031 & -.032 & $-.868^{*}$ & .015 & -.019 & .197 & .029 & -.017 & -.048 & .032 & .045 & $.043^{*}$ & $.164^{*}$ & .026 & $-.035^{*}$ \\
\hline Modest & .039 & -.007 & $-.074^{*}$ & -.056 & -.047 & $.124^{*}$ & $-.321^{*}$ & .033 & -.031 & $-.868^{*}$ & .018 & -.016 & .202 & .027 & -.017 & -.044 & .029 & .041 & $.038^{*}$ & $.134^{*}$ & .030 & $-.041^{*}$ \\
\hline \multicolumn{23}{|c|}{ Fresh vegetables } \\
\hline Well-off & $-.170^{*}$ & $-.103^{*}$ & .023 & -.031 & .106 & -.046 & $.896^{*}$ & -.050 & -.130 & .045 & $-.443^{*}$ & -.026 & .250 & $-.116^{*}$ & $.110^{*}$ & .101 & $-.161^{*}$ & $.446^{*}$ & $-.122^{*}$ & .058 & -.026 & $-.134^{*}$ \\
\hline Avg upper & $-.163^{*}$ & $-.094^{*}$ & .021 & -.037 & .100 & -.041 & $.805^{*}$ & -.057 & -.122 & .044 & $-.398^{*}$ & -.021 & .303 & $-.105^{*}$ & .10 & .110 & $-.146^{*}$ & $.427^{*}$ & $-.107^{*}$ & .044 & -.027 & $-.159 *$ \\
\hline Avg lower & $-.162^{*}$ & $-.090^{*}$ & .019 & -.045 & .102 & -.035 & $.798^{*}$ & -.063 & -.107 & .041 & $-.305^{*}$ & -.016 & .365 & $-.094^{*}$ & $.104^{*}$ & .116 & $-.139 *$ & $.407^{*}$ & $-.094^{*}$ & .035 & -.030 & $-.187^{*}$ \\
\hline Modest & $-.177^{*}$ & -.095 & .019 & -.053 & .103 & -.028 & $.810^{*}$ & -.065 & -.098 & .039 & $-.204^{*}$ & -.012 & .370 & $-.084^{*}$ & $.098^{*}$ & .115 & $-.128^{*}$ & $.368^{*}$ & $-.082^{*}$ & .027 & -.034 & $-.224^{*}$ \\
\hline \multicolumn{23}{|c|}{ Milk products } \\
\hline Well-off & .122 & $-.131^{*}$ & .075 & -.067 & -.027 & $.260^{*}$ & .085 & -.042 & $.651^{*}$ & 197 & $-.103^{*}$ & .137 & $-.623^{*}$ & $-.780^{*}$ & -.103 & .008 & -.249 & $.382^{*}$ & $-.110^{*}$ & $.683^{*}$ & -.055 & -.042 \\
\hline Avg upper & .116 & $-.121^{*}$ & .068 & -.074 & -.027 & $.239^{*}$ & .076 & -.051 & $.620^{*}$ & .200 & $-.110^{*}$ & .115 & $-.757^{*}$ & $-.800^{*}$ & -.101 & .003 & -.221 & $.371^{*}$ & $-.098^{*}$ & $.532^{*}$ & -.056 & -.046 \\
\hline Avg lower & .115 & $-.118^{*}$ & .065 & -.080 & -.030 & $.216^{*}$ & .074 & -.062 & $.579^{*}$ & 198 & $-.125^{*}$ & .102 & $-.923^{*}$ & $-.818^{*}$ & -.096 & -.005 & -.203 & $.363^{*}$ & $-.090^{*}$ & $.441^{*}$ & -.060 & -.044 \\
\hline Modest & .125 & $-.126^{*}$ & .065 & -.083 & -.034 & $.184^{*}$ & .073 & -.070 & $.558^{*}$ & .203 & $-.140^{*}$ & .089 & $-.942^{*}$ & $-.837^{*}$ & -.090 & -.016 & -.179 & $.339^{*}$ & $-.082^{*}$ & $.363^{*}$ & -.067 & -.040 \\
\hline \multicolumn{23}{|c|}{ Cheese/butter/cream category } \\
\hline Well-off & -.080 & $.209^{*}$ & -.060 & -.068 & $-.601^{*}$ & -.298 & .267 & $-.193^{*}$ & -.590 & -.089 & $.167^{*}$ & .079 & -.080 & $-.180^{*}$ & $-.254^{*}$ & -.118 & $.378^{*}$ & $-1.548^{*}$ & $-.285^{*}$ & -.317 & .034 & .040 \\
\hline Avg upper & -.077 & $.191^{*}$ & -.054 & -.076 & $-.561^{*}$ & -.277 & .240 & $-.229^{*}$ & -.569 & -.089 & $.181^{*}$ & .066 & -.095 & $-.166^{*}$ & $-.262^{*}$ & -.127 & $.340^{*}$ & $-1.486^{*}$ & $-.253^{*}$ & -.246 & .036 & .049 \\
\hline Avg lower & -.077 & $.185^{*}$ & -.051 & -.085 & $-.555^{*}$ & $-.254^{*}$ & .237 & $-.263^{*}$ & -.542 & -.086 & $.211^{*}$ & .060 & -.115 & $-.153^{*}$ & -.2 & -.127 & $.318^{*}$ & $-1.435^{*}$ & $-.227^{*}$ & -.202 & .038 & .057 \\
\hline Modest & -.085 & $.196^{*}$ & -.051 & -.093 & $-.543^{*}$ & $-.220^{*}$ & .240 & $-.282^{*}$ & -.532 & -.087 & $.242^{*}$ & .054 & -.118 & $-.139^{*}$ & $-.303^{*}$ & -.118 & $.286^{*}$ & $-1.312^{*}$ & $-.202^{*}$ & -.165 & .043 & .067 \\
\hline \multicolumn{23}{|c|}{ Prepared meals } \\
\hline Well-off & $-.166^{*}$ & .064 & -.113 & $.698^{*}$ & .054 & $-.244^{*}$ & $-.643^{*}$ & .076 & -.378 & -.077 & $.182^{*}$ & -.106 & $.677^{*}$ & .049 & -.000 & $-1.389^{*}$ & -.103 & $-.364^{*}$ & $-.115^{*}$ & $-.699^{*}$ & -.047 & -.009 \\
\hline Avg upper & $-.159^{*}$ & .059 & -.103 & $.787^{*}$ & .053 & $-.223^{*}$ & $-.576^{*}$ & .093 & -.355 & -.081 & $.195^{*}$ & -.087 & $.821^{*}$ & .047 & -.002 & $-1.399^{*}$ & -.096 & $-.355^{*}$ & $-.100^{*}$ & $-.545^{*}$ & -.048 & -.017 \\
\hline Avg lower & $-.159^{*}$ & .057 & -.097 & $.889^{*}$ & .052 & $-.205^{*}$ & $-.570^{*}$ & 106 & -.338 & -.078 & $.227^{*}$ & -.080 & $1.010^{*}$ & .043 & -.002 & $-1.396^{*}$ & -.089 & $-.341^{*}$ & $-.090^{*}$ & $-.449^{*}$ & -.052 & -.017 \\
\hline Modest & $-.176^{*}$ & .059 & -.096 & $.978^{*}$ & .046 & $-.181^{*}$ & $-.580^{*}$ & .109 & -.343 & -.075 & $.264^{*}$ & -.076 & $1.053^{*}$ & .036 & .001 & $-1.377^{*}$ & -.076 & $-.305^{*}$ & $-.082^{*}$ & $-.365^{*}$ & -.058 & -.008 \\
\hline \multicolumn{23}{|c|}{ Sugar-fat products } \\
\hline Well-off & -.053 & -.003 & $-.250^{*}$ & .035 & $-.336^{*}$ & $-.231^{*}$ & .242 & $-.160^{*}$ & -.207 & $.296^{*}$ & $-.120^{*}$ & -.114 & .023 & -.118 & $-.205^{*}$ & $-.208^{*}$ & $.277^{*}$ & $.434^{*}$ & $-.244^{*}$ & .341 & -.019 & $.100^{*}$ \\
\hline Avg upper & -.052 & -.003 & $-.226^{*}$ & .043 & $-.316^{*}$ & $-.216^{*}$ & .215 & $-.191^{*}$ & -.208 & $.302^{*}$ & $-.128^{*}$ & -.101 & .035 & $-.111^{*}$ & $-.200^{*}$ & $-.227^{*}$ & $.252^{*}$ & $.423^{*}$ & $-.335^{*}$ & .267 & -.019 & $.124^{*}$ \\
\hline Avg lower & -.053 & -.004 & $-.213^{*}$ & .053 & $-.317^{*}$ & $-.201^{*}$ & .211 & $-.223^{*}$ & -.208 & $.299^{*}$ & $-.145^{*}$ & -.096 & .052 & $-.105^{*}$ & $-.192^{*}$ & $-.236^{*}$ & $.240^{*}$ & $.416^{*}$ & -.4 & .223 & -.020 & $.150^{*}$ \\
\hline Modest & -.061 & -.006 & $-.211^{*}$ & .065 & $-.315^{*}$ & $-.179^{*}$ & .212 & $-.245^{*}$ & -.219 & $.305^{*}$ & $-.161^{*}$ & -.091 & .068 & $-.100^{*}$ & $-.182^{*}$ & $-.233^{*}$ & $.221^{*}$ & $.389^{*}$ & $-.476^{*}$ & .185 & -.021 & $.189^{*}$ \\
\hline \multicolumn{23}{|c|}{ Other soft drinks } \\
\hline Well-off & .039 & $.062^{*}$ & -.036 & -.000 & .074 & -.072 & $-.345^{*}$ & .036 & .184 & $.141^{*}$ & .009 & .093 & -.217 & $.082^{*}$ & -.035 & $-.126^{*}$ & .079 & $-.295^{*}$ & .035 & $-.984^{*}$ & -.042 & $-.030^{*}$ \\
\hline Avg upper & .037 & $.057^{*}$ & -.032 & .001 & .068 & -.068 & $-.311^{*}$ & .041 & .173 & $.143^{*}$ & .01 & .078 & -.263 & $.075^{*}$ & -.034 & $-.135^{*}$ & .073 & $-.281^{*}$ & .030 & $-.986^{*}$ & -.043 & $-.033^{*}$ \\
\hline Avg lower & .036 & $.054^{*}$ & -.030 & .002 & .066 & -.063 & $-.308^{*}$ & .046 & .161 & $.141^{*}$ & .01 & .070 & -.320 & $.068^{*}$ & -.032 & $-.136^{*}$ & .069 & $-.270^{*}$ & .026 & $-.988^{*}$ & -.046 & $-.035^{*}$ \\
\hline Modest & .040 & $.057^{*}$ & -.030 & .004 & .064 & -.056 & $-.313^{*}$ & .048 & .155 & $.143^{*}$ & .015 & .062 & -.328 & $.061^{*}$ & -.031 & $-.129^{*}$ & .063 & $-.245^{*}$ & .023 & $-.990^{*}$ & -.052 & $-.037^{*}$ \\
\hline
\end{tabular}

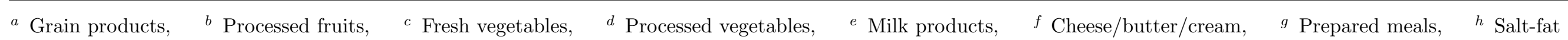
products, $\quad{ }^{i}$ Sugar-fat products, $\quad{ }^{j}$ Soft drinks, $\quad{ }^{k}$ Average upper, $\quad{ }^{l}$ Average lower.

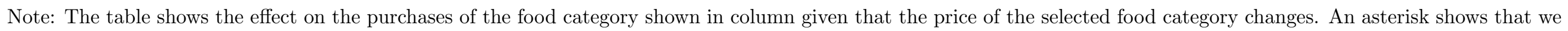
can reject the null hypothesis that the elasticity is zero at the $5 \%$ level. 
Table 5. Nutrient Elasticities Across Income Class

\begin{tabular}{|c|c|c|c|c|c|c|c|c|c|c|c|c|c|c|c|c|c|c|c|c|c|c|}
\hline & $\begin{array}{l}\text { Red } \\
\text { meat }\end{array}$ & $\begin{array}{l}\text { Other } \\
\text { meats }\end{array}$ & $\begin{array}{l}\text { Cooked } \\
\text { meats }\end{array}$ & d Fish & Egg & Grain $^{a}$ & Potato & $\begin{array}{l}\begin{array}{l}\text { Fresh } \\
\text { fruits }\end{array} \\
\text { a }\end{array}$ & $\begin{array}{l}\text { Pro }^{b} \\
\text { fruits }\end{array}$ & $\begin{array}{l}\text { Fruit } \\
\text { juice }\end{array}$ & $\begin{array}{l}\text { Fres }^{c} \\
\text { veget }\end{array}$ & $\begin{array}{l}\begin{array}{l}\text { Pro } \\
\text { veget }\end{array}\end{array}$ & $\begin{array}{l}\text { Dried } \\
\text { fruit }\end{array}$ & Milk $^{e}$ & Cheese $^{f}$ & $\begin{array}{l}\text { Pre }^{g} \\
\text { meal }\end{array}$ & 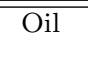 & $\begin{array}{l}\text { Salt } \underline{h} \\
\text { fat }\end{array}$ & $\begin{array}{l}\text { Sug }^{i} \\
\text { fat }\end{array}$ & 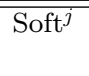 & Water & 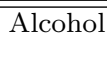 \\
\hline \multicolumn{23}{|c|}{ Energy } \\
\hline Well-off & -.069 & -.039 & -.109 & .022 & -.001 & -.080 & -.022 & -.084 & -.022 & -.002 & -.020 & -.007 & -.005 & -.088 & -.123 & -.142 & -.031 & -.012 & -.079 & -.019 & .000 & -.098 \\
\hline Avg upper ${ }^{k}$ & -.066 & -.042 & -.111 & .022 & -.001 & -.082 & -.024 & -.073 & -.022 & -.003 & -.017 & -.007 & -.004 & -.092 & -.119 & -.133 & -.042 & -.012 & -.092 & -.022 & -.000 & -.085 \\
\hline Avg lower ${ }^{l}$ & -.065 & -.041 & -.110 & .024 & -.002 & -.088 & -.023 & -.065 & -.021 & -.002 & -.015 & -.008 & -.003 & -.097 & -.120 & -.128 & -.047 & -.013 & -.107 & -.025 & .001 & -.075 \\
\hline Modest & -.059 & -.037 & -.105 & .025 & -.002 & -.095 & -.022 & -.060 & -.020 & -.002 & -.012 & -.008 & -.003 & -.100 & -.117 & -.128 & -.057 & -.013 & -.120 & -.028 & -.000 & -.065 \\
\hline \multicolumn{23}{|c|}{ Saturated fat } \\
\hline Well-off & -.058 & .050 & -.129 & -.002 & -.027 & -.032 & .001 & -.092 & -.028 & -.001 & .008 & .003 & -.003 & -.139 & -.172 & -.114 & -.010 & -.045 & -.146 & -.006 & -.002 & -.052 \\
\hline Avg upper & -.054 & .045 & -.131 & -.003 & -.026 & -.031 & .001 & -.087 & -.026 & -.001 & .008 & .003 & -.003 & -.141 & -.168 & -.104 & -.018 & -.043 & -.157 & -.005 & -.002 & -.049 \\
\hline Avg lower & -.053 & .041 & -.130 & -.001 & -.026 & -.030 & .001 & -.082 & -.025 & -.001 & .008 & .003 & -.002 & -.142 & -.170 & -.100 & -.022 & -.042 & -.168 & -.005 & -.002 & -.047 \\
\hline Modest & -.048 & .041 & -.124 & -.000 & -.025 & -.030 & .001 & -.077 & -.024 & -.001 & .008 & .003 & -.002 & -.143 & -.172 & -.100 & -.031 & -.040 & -.179 & -.005 & -.002 & -.045 \\
\hline \multicolumn{23}{|c|}{ Polyunsaturated fat } \\
\hline Well-off & -.027 & -.047 & -.191 & -.019 & .103 & .028 & -.045 & -.086 & -.132 & .020 & -.079 & -.027 & .001 & -.151 & .113 & -.172 & -.222 & .146 & .106 & .026 & -.059 & -.073 \\
\hline Avg upper & -.024 & -.044 & -.180 & -.018 & .095 & .026 & -.042 & -.082 & -.123 & .019 & -.073 & -.025 & .001 & -.141 & .106 & -.156 & -.269 & .136 & .095 & .025 & -.055 & -.070 \\
\hline Avg lower & -.023 & -.042 & -.173 & -.014 & .089 & .022 & -.040 & -.078 & -.115 & .018 & -.069 & -.023 & .002 & -.132 & .096 & -.149 & -.292 & .125 & .082 & .023 & -.052 & -.068 \\
\hline Modest & -.022 & -.038 & -.160 & -.012 & .082 & .018 & -.037 & -.071 & -.106 & .016 & -.064 & -.021 & .002 & -.121 & .089 & -.142 & -.333 & .114 & .071 & .022 & -.048 & -.067 \\
\hline \multicolumn{23}{|c|}{ Beta-carotene } \\
\hline Well-off & -.100 & -.127 & .012 & -.068 & .016 & -.003 & .084 & -.068 & -.012 & -.002 & -.318 & -.042 & .007 & -.085 & .080 & .113 & -.038 & .047 & -.119 & .016 & .013 & -.290 \\
\hline Avg upper & -.108 & -.133 & .015 & -.073 & .017 & -.003 & .091 & -.053 & -.013 & -.002 & -.286 & -.050 & .008 & -.092 & .088 & .123 & -.042 & .051 & -.127 & .017 & .013 & -.313 \\
\hline Avg lower & -.116 & -.149 & .015 & -.082 & .018 & -.003 & .098 & -.043 & -.015 & -.003 & -.207 & -.068 & .009 & -.101 & .091 & .132 & -.048 & .055 & -.142 & .020 & .015 & -.344 \\
\hline Modest & -.130 & -.161 & .018 & -.089 & .020 & -.003 & .109 & -.039 & -.016 & -.003 & -.134 & -.079 & .011 & -.110 & .101 & .146 & -.054 & .061 & -.154 & .021 & .015 & -.380 \\
\hline \multicolumn{23}{|c|}{ Vitamin C } \\
\hline Well-off & .059 & -.121 & -.122 & -.132 & -.001 & .040 & -.032 & -.103 & -.005 & -.204 & -.082 & -.025 & .008 & -.001 & -.049 & -.012 & -.024 & .011 & -.023 & .029 & .020 & -.246 \\
\hline Avg upper & .061 & -.129 & -.130 & -.140 & -.000 & .042 & -.039 & -.052 & -.006 & -.214 & -.068 & -.031 & .009 & -.005 & -.050 & -.009 & -.026 & .012 & -.026 & .028 & .020 & -.262 \\
\hline Avg lower & .068 & -.137 & -.142 & -.149 & -.001 & .045 & -.043 & -.010 & -.007 & -.235 & -.035 & -.039 & .009 & -.007 & -.058 & -.013 & -.027 & .012 & -.028 & .029 & .023 & -.276 \\
\hline Modest & .068 & -.141 & -.147 & -.152 & -.000 & .046 & -.044 & .010 & -.007 & -.243 & -.006 & -.044 & .010 & -.011 & -.056 & -.015 & -.028 & .013 & -.029 & .027 & .022 & -.286 \\
\hline \multicolumn{23}{|c|}{ Calcium } \\
\hline Well-off & .040 & .019 & -.024 & -.079 & -.017 & .004 & .001 & -.062 & .019 & .000 & -.022 & .020 & -.016 & -.300 & -.172 & -.014 & -.005 & -.054 & -.132 & .007 & -.151 & -.110 \\
\hline Avg upper & .039 & .018 & -.024 & -.075 & -.017 & .003 & .000 & -.055 & .018 & .000 & -.018 & .018 & -.015 & -.319 & -.170 & -.011 & -.006 & -.052 & -.133 & .006 & -.147 & -.105 \\
\hline Avg lower & .037 & .016 & -.024 & -.070 & -.017 & .001 & .000 & -.050 & .017 & .000 & -.012 & .016 & -.014 & -.343 & -.174 & -.011 & -.006 & -.051 & -.136 & .006 & -.132 & -.099 \\
\hline Modest & .036 & .017 & -.023 & -.065 & -.016 & -.001 & .000 & -.046 & .017 & .000 & -.007 & .014 & -.013 & -.362 & -.176 & -.014 & -.006 & -.050 & -.137 & .004 & -.122 & -.093 \\
\hline \multicolumn{23}{|c|}{ Sodium } \\
\hline Well-off & -.025 & .011 & -.196 & .034 & -.021 & -.049 & -.026 & -.064 & -.005 & -.031 & .044 & -.028 & .005 & -.037 & -.156 & -.235 & .000 & -.066 & -.150 & -.042 & -.017 & -.091 \\
\hline Avg upper & -.024 & .008 & -.210 & .038 & -.021 & -.050 & -.030 & -.059 & -.004 & -.030 & . 045 & -.033 & .005 & -.042 & -.151 & -.216 & -.001 & -.065 & -.153 & -.041 & -.017 & -.084 \\
\hline Avg lower & -.023 & .007 & -.219 & .044 & -.021 & -.053 & -.027 & -.056 & -.004 & -.028 & .046 & -.037 & .005 & -.048 & -.152 & -.209 & -.001 & -.064 & -.159 & -.039 & -.014 & -.079 \\
\hline Modest & -.021 & .008 & -.212 & .050 & -.020 & -.058 & -.027 & -.053 & -.004 & -.028 & .049 & -.040 & .005 & -.053 & -.150 & -.217 & -.002 & -.064 & -.165 & -.040 & -.014 & -.073 \\
\hline \multicolumn{23}{|c|}{ Magnesium } \\
\hline Well-off & -.030 & -.066 & -.053 & -.026 & .007 & -.060 & -.027 & -.064 & .015 & -.022 & -.023 & -.010 & -.010 & -.092 & -.129 & -.096 & -.003 & -.047 & -.070 & -.023 & -.109 & -.127 \\
\hline Avg upper & -.029 & -.070 & -.056 & -.022 & .007 & -.064 & -.033 & -.050 & .015 & -.023 & -.015 & -.013 & -.009 & -.102 & -.126 & -.091 & -.004 & -.048 & -.079 & -.025 & -.109 & -.115 \\
\hline Avg lower & -.031 & -.071 & -.058 & -.015 & .006 & -.073 & -.031 & -.041 & .015 & -.021 & -.005 & -.017 & -.008 & -.115 & -.132 & -.092 & -.003 & -.050 & -.092 & -.025 & -.100 & -.104 \\
\hline Modest & -.027 & -.067 & -.057 & -.010 & .006 & -.083 & -.031 & -.035 & .015 & -.022 & .004 & -.019 & -.007 & -.127 & -.129 & -.098 & -.004 & -.051 & -.102 & -.028 & -.095 & -.095 \\
\hline
\end{tabular}

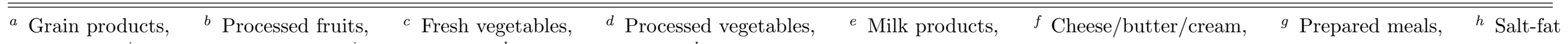
products, $\quad i$ Sugar-fat products, $\quad j$ Soft drinks, $\quad k$ Average upper, $\quad l$ Average lower.

Note: The table shows the effects on the purchases of the selected nutrients given that the price of the food category shown in the column changes. 
Table 6. Percentage of Quantity Change in Total Nutrients Purchased for Modest and Well-Off Households if Cheese/Butter/Cream, Sugar-Fat-Product, and/or Prepared-Meal Prices Increase by 10\%, Over a Four-Week Period

\begin{tabular}{|c|c|c|c|c|c|c|c|c|}
\hline \multirow[t]{2}{*}{ Tax base } & \multicolumn{2}{|c|}{ "Cheese/butter/cream } & \multicolumn{2}{|c|}{ Prepared meals } & \multicolumn{2}{|c|}{ Sugar-fat products } & \multicolumn{2}{|c|}{ Targeted products } \\
\hline & Well-off & Modest & Well-off & Modest & Well-off & Modest & Well-off & Modest \\
\hline Energy & -1.229 & -1.167 & -1.424 & -1.278 & -0.789 & -1.196 & -3.443 & -3.641 \\
\hline Protein & -1.139 & -1.150 & -0.603 & -0.604 & -1.163 & -1.294 & -2.904 & -3.049 \\
\hline Vegetal protein & -1.981 & -1.739 & -2.295 & -2.062 & -1.078 & -1.569 & -5.353 & -5.370 \\
\hline Animal protein & -0.924 & -0.991 & -0.049 & -0.088 & -1.163 & -1.191 & -2.135 & -2.270 \\
\hline Carbohydrate & -2.001 & -1.679 & -2.060 & -1.766 & -0.974 & -1.639 & -5.035 & -5.084 \\
\hline Sugar & -1.831 & -1.622 & -0.623 & -0.564 & -0.741 & -1.561 & -3.195 & -3.747 \\
\hline Starch & -2.229 & -1.747 & -4.082 & -3.271 & -1.277 & -1.684 & -7.588 & -6.701 \\
\hline Fat & -0.913 & -0.932 & -1.416 & -1.224 & -0.730 & -1.051 & -3.058 & -3.207 \\
\hline Saturated fat & -1.719 & -1.723 & -1.137 & -0.996 & -1.461 & -1.791 & -4.317 & -4.510 \\
\hline Monounsaturated fat & -0.901 & -0.896 & -1.642 & -1.420 & -0.691 & -1.029 & -3.234 & -3.345 \\
\hline Polyunsaturated fat & 1.127 & 0.892 & -1.723 & -1.419 & 1.064 & 0.710 & 0.467 & 0.183 \\
\hline Cholesterol & -2.179 & -2.113 & -0.488 & -0.482 & -1.837 & -2.100 & -4.503 & -4.694 \\
\hline Alcohol & 0.393 & 0.653 & -0.103 & -0.098 & 0.992 & 1.859 & 1.281 & 2.414 \\
\hline Fibers & -1.031 & -1.040 & -1.085 & -1.144 & -1.045 & -1.502 & -3.161 & -3.686 \\
\hline Retinol & -0.955 & -1.037 & 0.057 & 0.031 & -1.520 & -1.602 & -2.419 & -2.608 \\
\hline Beta-carotene & 0.800 & 1.015 & 1.130 & 1.460 & -1.189 & -1.537 & 0.742 & 0.937 \\
\hline Vit $B 1$ & -0.991 & -0.919 & -2.013 & -1.899 & -1.271 & -1.494 & -4.275 & -4.312 \\
\hline Vit B2 & -1.352 & -1.292 & -0.362 & -0.350 & -1.269 & -1.426 & -2.983 & -3.068 \\
\hline Vit B3 & -0.454 & -0.453 & -0.771 & -0.804 & -0.838 & -0.937 & -2.064 & -2.194 \\
\hline Vit B5 & -1.132 & -1.105 & -0.452 & -0.457 & -1.114 & -1.289 & -2.698 & -2.851 \\
\hline Vit $B 6$ & -0.752 & -0.755 & -1.116 & -1.141 & -0.956 & -1.103 & -2.824 & -2.999 \\
\hline Vit $B 9$ & -0.850 & -0.931 & -0.250 & -0.286 & -1.205 & -1.513 & -2.305 & -2.730 \\
\hline Vit B12 & -0.643 & -0.735 & 0.970 & 0.906 & -0.871 & -0.960 & -0.543 & -0.789 \\
\hline Vit $C$ & -0.492 & -0.562 & -0.115 & -0.154 & -0.233 & -0.290 & -0.840 & -1.007 \\
\hline Vit $D$ & -2.057 & -2.213 & 2.303 & 2.272 & -1.225 & -1.675 & -0.979 & -1.616 \\
\hline Vit $E$ & 1.524 & 1.247 & -1.134 & -0.940 & 1.271 & 0.914 & 1.661 & 1.221 \\
\hline Iron & -1.723 & -1.760 & -0.135 & -0.138 & -1.318 & -1.373 & -3.176 & -3.271 \\
\hline Calcium & -1.142 & -1.124 & -0.822 & -0.831 & -0.905 & -1.233 & -2.869 & -3.188 \\
\hline Magnesium & -1.286 & -1.286 & -0.960 & -0.977 & -0.700 & -1.021 & -2.945 & -3.285 \\
\hline Sodium & -1.562 & -1.499 & -2.351 & -2.167 & -1.502 & -1.651 & -5.415 & -5.317 \\
\hline Phosphorus & -1.533 & -1.522 & -0.502 & -0.493 & -1.184 & -1.340 & -3.219 & -3.355 \\
\hline Potassium & -0.634 & -0.652 & -0.613 & -0.659 & -0.647 & -0.879 & -1.894 & -2.190 \\
\hline
\end{tabular}

a By targeted products, we mean cheese/butter/cream, prepared meals, and sugar-fat products.

Note: The table shows the effects on nutrients purchased given that the price of the food category shown in the column changes. 